\title{
EYEWITNESS EXPERT TESTIMONY AND JURY DECISIONMAKING
}

\author{
Steven D. Penrod* and Brian L. Cutler $\dagger$
}

\section{INTRODUCTION}

In cases where the reliability of an eyewitness identification is in question, psychologists are sometimes called as expert witnesses to educate jurors about factors that may influence eyewitness accuracy. There is considerable debate within both the legal and psychological communities about whether this testimony should be admitted. Proponents and opponents of expert testimony disagree over whether there is adequate scientific foundation for such testimony, whether the evidence offered by the expert is beyond the ken of the jury, and whether expert testimony is likely to improve or impair jury decisionmaking. We report a series of studies that examine these three issues empirically.

The first study reviews experiments on facial recognition performance. The review identifies a number of factors that have substantial and reliable effects on eyewitness performance.

In a second set of studies, mock jurors are shown different versions of a realistic videotaped criminal trial in which the primary evidence is the identification of the defendant by an eyewitness. Evidence concerning the crime and the identification procedures is systematically varied through the testimony of the eyewitness and the police officer in charge of the investigation. These studies indicate that jurors' evaluations of identification evidence are not influenced by factors that are known to affect identification accuracy. Instead, jurors are influenced by the confidence of the eyewitness. Unfortunately, a number of studies indicate that confidence is only weakly related to the accuracy of the identifications.

In a third set of studies, the videotaped trials include expert psychological testimony. In the first study, expert testimony improves the sensitivity of

\footnotetext{
Copyright $(\mathcal{O} 1989$ by Law and Contemporary Problems

* Professor of Law, University of Minnesota.

$\dagger$ Assistant Professor of Psychology, Florida International University.

Much of the research described here was funded by National Science Foundation Grant No. SES8411721 to Steven Penrod. We wish to express gratitude to attorneys Lyn Opelt and Stephen Rogers for playing the roles of attorneys in the videotaped trial, and Hedy Red Dexter, Todd Martens, and Tom Stuve for their assistance with the creation of the trial tapes and collection of data. Thoughtful comments on the research have been provided by Patricia Devine, Stephen Herzberg, Arie Kruglanski, Carol Ryff, and others. The organizational and professional skills of James Coward were invaluable.
} 
jurors to eyewitness evidence. When expert testimony is presented, jurors do take witnessing and identification factors into consideration and rely less on the confidence of the witness. The study also shows that expert psychological testimony does not simply increase jurors' general skepticism about eyewitness evidence. Other experiments examine the influence of different forms of expert testimony and judicial instructions on jurors' judgments. A court-appointed expert produces only skepticism. A defense-hired expert produces some sensitization to witnessing and identification evidence, but no skepticism. Opposing experts (defense- and prosecution-hired) produce the largest effects on both sensitization and skepticism. Judges' instructions, designed to aid the jury in evaluating eyewitness evidence, have no beneficial effect on jury decisionmaking.

\section{Can Expert Testimony Improve Juror Decisionmaking?}

The focus of the research reported here is jurors' use of scientific evidence. Because of rapid technological advances in virtually all branches of scientific endeavor, courts are increasingly being offered scientific evidence and expert testimony. Expert testimony is also increasingly accepted into evidence." In contrast to the restrictive approaches of the common law, the Federal Rules of Evidence ${ }^{2}$ and their state progeny hold a relatively liberal view on the admissibility of expert testimony. Under Rule 702 of the Federal Rules, a person "qualified as an expert by knowledge, skill, experience, training, or education" may testify if such testimony will assist jurors in evaluating a fact in issue. ${ }^{3}$ As part of the liberalized treatment of experts, courts are now admitting empirically based evidence and testimony on such varied issues as obscenity, ${ }^{4}$ dangerousness, ${ }^{5}$ post-traumatic stress syndromes, ${ }^{6}$ the effects of pretrial publicity on people's attitudes toward a defendant, ${ }^{7}$ and the reliability of eyewitness identification. ${ }^{8}$ The research treated in this article examines issues associated with expert psychological testimony on eyewitness identification.

Psychologists and legal scholars have long been aware of the fallibility of eyewitness memory. The earliest experimental research on eyewitness memory can be traced back to A. Binet and J. M. Cattell at the turn of the

1. See, e.g., The Evolving Role of Statistical Assessments as Evidence in the Courts (S. Fienberg ed. 1989); J. Monahan \& L. Walker, Social Science in Law: Cases and Materials (2d ed. 1990).

2. FED. R. EvID. 702 (1975).

3. Id.

4. Saliba v. State, 475 N.E.2d 1181 (Ind. Ct. App. 1985).

5. Barefoot v. Estelle, 463 U.S. 880 (1983). (1982)

6. Henson v. State, 535 N.E.2d 1189 (Ind. 1989); State v. Marks, 231 Kan. 645, 647 P.2d 1292

7. Firestone v. Crown Center Redevelopment Corp., 693 S.W.2d 99 (Mo. 1985) (en banc).

8. Arizona v. Chapple, 135 Ariz. 281, 660 P.2d 1208 (1983). 
century. ${ }^{9}$ Among the early legal scholars, Borchard offered an impressive collection of cases in which miscarriages of justice had been documented. ${ }^{10}$ Mistaken identification was the single most common cause of injustice in Borchard's collection. " Wigmore recognized the potential for improving the accuracy of identifications from lineup tests with the use of psychological research and sophisticated videotape equipment. ${ }^{12}$ Half a century later, this potential has yet to be fully realized.

The acceptance of expert psychological testimony on issues associated with eyewitness memory is currently a topic of heated debate. ${ }^{13}$ The appropriateness of expert psychological testimony has been addressed on moral and legal grounds. ${ }^{14} \mathrm{~A}$ considerable portion of the debate centers around three empirical questions: (1) What are the quality and external validity of the memory research on which expert testimony is based?, (2) Is psychological knowledge about eyewitness memory beyond the ken of the jury?, and (3) What are the effects of expert psychological testimony on jury decisionmaking? ${ }^{15}$ These questions arise in both the psychological and legal literature; to date, the empirical evidence addressing these questions is inconclusive.

\section{III}

\section{The Quality of The Research on Which EXPERT} TESTIMONY IS BASED

\section{A. Critiques of Eyewitness Research}

Some psychologists doubt that the existing body of research and theory on human memory is sufficient to draw valid conclusions about eyewitness

9. Whipple, The Observer as Reporter: A Survey of the Psychology of Testimony, 6 PsychoLOGICAL Bull. 153, 154, 170 n.8 (1909).

10. E. Borchard, Convicting the Innocent: Errors of Criminal Justice (1932).

11. Id. at xiii.

12. Wigmore, Evidence-Corroboration by Witness' Identification of an Accused on Arrest, 25 ILL. L. REV. $550,551(1931)$.

13. See Loftus \& Schneider, "Behold with Strange Surprise": Judicial Reactions to Expert Testimony Concerning Eyewitness Reliability, 56 UMKC L. REv. 1 (1987); McCloskey \& Egeth, Eyewitness Identification: What Can a Psychologist Tell a Jury?, 38 AM. Psychologist 550 (1983); see also 10 LAw \& Hum. Behav. 1, 1-181 (1986) (issue devoted entirely to psychological testimony).

14. Bermant, Two Conjectures about the Issue of Expert Testimony, 10 LAW \& HuM. BEHAv. 97 (1986); Bersoff, Psychologists and the Judicial System: Broader Perspectives, 10 LAw \& Hum. BeHav. 151 (1986); Buckhout, Personal Values and Expert Testimony, 10 Law \& Hum. Behav. 127 (1986); Goldman, Cognitive Psychologists as Expert Witnesses: A Problem in Professional Ethics, 10 LAw \& Hum. Benav. 29 (1986); Hastie, Notes on the Psychologist Expert Witness, 10 Law \& Hum. Behav. 79 (1986); Lempert, Social Science in Court: On "Eyewitness Experts" and Other Issues, 10 Law \& Hum. Behav. 167 (1986); Loftus, Experimental Psychologist as Advocate or Impartial Educator, 10 LAW \& HuM. BEHAV. 63 (1986); Loftus, Ten Years in the Life of An Expert Witness, 10 LAW \& HuM. BEHAv. 241 (1986); Woocher, Legal Principles Governing Expert Testimony by Experimental Psychologists, 10 Law \& Hum. Behav. 47 (1986).

15. Konecni \& Ebbesen, Courtroom Testimony by Psychologists on Eyewilness Identification Issues: Critical Notes and Reflections, 10 LAw \& Hum. BeHav. 117, 121 (1986); McCloskey, Egeth \& McKenna, The Experimental Psychologist in Court: The Ethics of Expert Testimony, 10 LAW \& HuM. BeHav. 1, 6-7, 8-10 (1986); Wells, Experi Psychological Testimony: Empirical and Conceptual Analyses of Effects, 10 LAw \& Hum. BeHav. 83 (1986); Yarmey, Ethical Responsibilities Governing the Statements Experimental Psychologists Make in Expert Testimony, 10 LAW \& Hum. BEHav. 101, 107, 112 (1986). 
memory. ${ }^{16}$ The primary issues raised by these psychologists are that the body of scientific research examining eyewitness reliability is not sufficiently large to provide a basis for scientific conclusions, ${ }^{17}$ that there is disagreement about memory processes and the consistency of the research findings, ${ }^{18}$ and that the research techniques and subject populations used do not justify generalization of the findings to actual crime settings. ${ }^{19}$

Konecni and Ebbesen have argued vehemently that a failure to sample situations and populations renders memory research inapplicable to the actual eyewitness setting: "Almost all studies which form the basis for expert testimony in this area are simulations. Virtually none of these simulations have been validated in terms of the real-world situations, stimuli, and subject samples ...."'20

On the other hand, many psychologists have argued that certain factors predictably influence identification accuracy at the perception, encoding, storage, and retrieval stages of memory, ${ }^{21}$ regardless of the circumstances under which the identification is made. Of course the consistency of research findings and the extent to which memory and eyewitness testimony research generalizes to actual criminal cases are ultimately empirical questions.

\section{B. Assessing the Research}

One way to examine the consistency and coherence of the research findings is to use existing research as a data base for further, secondary study. Shapiro and Penrod, for example, conducted a quantitative review or "metaanalysis" of facial recognition experiments. ${ }^{22}$ They examined the reliability of "questionable" findings such as the claimed impairment of performance in cross-racial identifications as compared to same-race identifications and the positive influence of context reinstatement ${ }^{23}$ on face recognition.

They analyzed the results of 128 eyewitness identification and facial recognition studies, involving 960 experimental conditions and 16,950 subjects. The study was designed to address two general questions: First, what knowledge have psychologists accumulated on factors that reliably influence facial identification performance? Second, what areas of facial identification research would benefit from further research?

16. See Konecni \& Ebbesen, supra note 15, at 121; McCloskey, Egeth \& McKenna, supra note 15 , at 8-10; Pachella, Personal Values and the Value of Expert Testimony, 10 LAW \& Hum. BeHAv. 145 (1986).

17. McCloskey, Egeth \& McKenna, supra note 15, at 9.

18. Id.

19. Id. at 10

20. Konecni \& Ebbesen, supra note 15 , at 121.

21. B. Clifford \& R. Bull, The Psychology of Personal Identification (1978); E. Loftus, Eyewitness Testimony (1979); G. Weles \& E. Loftus, Eyewitness Testimony: Psychological Perspectives (1984) [hereinafter Eyewitness Testimony]; A. Yarmey, The Psychology of Eyewitness Testimony (1979); Penrod, Loftus \& Winkler, The Reliability of Eyewitness Testimony: A Psychological Perspective, in The Psychology of the Courtroom (R. Bray \& N. Kerr eds. 1982).

22. Shapiro \& Penrod, Meta-Analysis of Facial Identification Studies, 100 PsychologiCal. Bull. 139 (1986)

23. Context reinstatement refers to efforts to reinstate mentally the conditions under which observations were originally made. 
Two analytic techniques were employed: The first was an "effect size" analysis, which combined the effect sizes of eyewitness factors across studies that manipulated a particular factor. An effect size (indexed by $d$ ) reflects the magnitude of differences between two means (for example, the mean correct identification rate for male witnesses versus the mean correct identification rate for female witnesses) using a standard measure that permits comparisons across different variables. A $d$ of zero would indicate that two means are identical, while a $d$ of .3 (or -.3 ) would indicate a difference in means that, in the context of this study, is quite noteworthy. The larger the value of $d$, the larger the impact of a variable on identification accuracy.

In the effect size analysis, Shapiro and Penrod found that large numbers of variables operating at the encoding and retrieval stages produced significant and sometimes substantial effects on performance (see Table 1, which summarizes the impact of factors on correct identification rates). The variables included context reinstatement (efforts to reinstate in the witness' mind the conditions under which observations were originally made), transformations in the appearance of faces (such as disguises and changes in pose), depth of processing strategies (the mnemonic strategies employed by witnesses during the original viewing), target distinctiveness, exposure time, cross-racial identification, and the length of the retention interval. Though not reflected in Table 1, the analysis indicated that there was little correspondence between a factor's impact on correct identifications and that factor's impact on mis-identification rates. 
TABLE 1

Impact on Facial Recognition of Variables EXamined by

\section{EXPERIMENTERS}

Variable

1) Individual Differences

2) Encoding Instructions (High vs. Low)

3) Context Reinstatement (Yes vs. No)

4) Target Distinctiveness (High vs. Low)

5) Sex of Target (Male vs. Female)

6) Transformation (None vs. Disguise)

7 Race of Target (White vs. Minority)

8) Retention Interval (Short vs. Long)

9) Same vs. Cross-Race Identification

10) Same vs. Cross-Sex Identification

11) Live/Video vs. Still at Recognition

12) Elaboration at Exposure Time

13) Pose at Study (3/4 vs. Front-Profile)

14) Subject Age (Young vs. Old)

15) Training (Yes vs. No)

16) Exposure Time at Study

17) Live or Videotape vs. Still at Study

18) Grand Means for Knowledge of Recognition Task Grand Means for Entire Data Set
Correct

Identification

Rates +

\begin{tabular}{rrrlll} 
Studies & Subjects & \multicolumn{1}{c}{$d$} & $p$ & $H I$ & $L O$ \\
103 & 9699 & .13 & $* * *$ & & \\
29 & 1868 & .97 & $* * *$ & 74 & 66 \\
23 & 1684 & 1.91 & $* * *$ & 79 & 52 \\
22 & 2174 & 76 & $* * *$ & 70 & 60 \\
19 & 2052 & .02 & n.s. & 74 & 72 \\
19 & 2682 & 1.05 & $* * *$ & 75 & 54 \\
18 & 1894 & .24 & $*$ & 59 & 53 \\
18 & 1980 & .43 & $* * *$ & 61 & 51 \\
17 & 1571 & .53 & $* * *$ & 63 & 57 \\
13 & 1197 & .14 & $* * *$ & 76 & 72 \\
13 & 1807 & .07 & $*$ & 50 & 50 \\
10 & 362 & 1.00 & $* * *$ & 78 & 72 \\
10 & 1266 & .53 & $* * *$ & 66 & 54 \\
9 & 603 & 1.10 & $* * *$ & 70 & 58 \\
8 & 534 & .18 & n.s. & 65 & 61 \\
8 & 990 & .61 & $* * *$ & 69 & 57 \\
5 & 896 & .50 & $* *$ & 72 & $\mathbf{5 8}$ \\
5 & 703 & .10 & n.s. & 56 & 58 \\
& & & & & \\
443 & 44301 & .47 & & &
\end{tabular}

$*<.05 * *<.001 \quad * * *<.0001$

+ Numbers of subjects for hit rates are often smaller than numbers for effect sizes $(d)$ due to missing data.

The second evaluative technique was a "study characteristics" analysis in which the characteristics of all experimental cells in all of the studies were coded, and study results integrated, to examine the influence of study characteristics on performance. Study characteristics include the techniques, settings, and experimental conditions under which the studies were performed. This analysis permitted Shapiro and Penrod to assess the effect of viewing and identification circumstances on witness/subject performance when examined across previous studies. Some of the study characteristics examined (for example, exposure time and retention interval) also served as independent variables in many studies. The analyses of study characteristics are potentially more informative than the effect size analyses, since the former contain more than 950 correct identifications (based on judgments from more than 16,500 subjects), while the latter have fewer than thirty correct identifications (even though they are often based on between one and two thousand subjects). For variables that appear in both sets of analyses, each analysis can be considered a validity check for the other.

A problem of multicollinearity arose-that is, some study characteristics proved redundant because they varied together across the studies. This 
occurred largely because laboratory researchers made use of one set of procedures while field researchers characteristically made use of somewhat different procedures. For example, laboratory researchers frequently made use of greater numbers of faces for subjects to remember, exposed faces to subjects for shorter periods of times, and tested memory after shorter delay periods. To clarify the analyses and results, correlated variables were combined into groups for analysis and variables that were independent of one another were analyzed separately. Among the variables and groups considered in the analyses were: attention, which encompassed the degree that attention was focused on the targets, whether subjects had knowledge of the recognition task, and the mode of presentation at study; load at study, which included the number of targets at study, the number of faces at study, and the total exposure time at study; and load at recognition, which included the number of decoys, the number of total faces at recognition and the ratio of targets to decoys. Variables that were largely independent of one another and independent of the three main groups included pose, target sex, target race, number of seconds of exposure per target, retention interval, number of faces presented simultaneously at recognition, and laboratory (versus eyewitness) facial recognition studies.

In brief, Shapiro and Penrod found that when groups of variables and individual variables were considered alone, each of them accounted for a statistically significant portion of variance in eyewitness performance, with a group of "attention" and "study type" (laboratory versus field experiment) variables accounting for the largest shares. Even when Shapiro and Penrod conducted extremely conservative analyses in which the effects of all other variables were "partialled" (statistically controlled for), most variables and groups of variables still explained statistically, significant independent portions of variance in performance. In all, the eleven sets of variables accounted for a highly significant (and, arguably, forensically significant) 47 percent of the variance in correct identification rates. This means that nearly half the variability in identification performance could be explained by the variables included in the analyses.

\section{Summary}

It was especially noteworthy that, after controlling for the effects of other variables, "study type" accounted for only 3 percent of the variance in performance. In contrast, when considered separately, study type accounted for 35 percent of the variance. This result demonstrates that the laboratory/field distinction is almost entirely redundant with the variables that predict identification performance, and laboratory/field differences in performance are largely accounted for by variations in attention, knowledge, mode of presentation, exposure time, number of targets, and target race. In other words, the argument that laboratory simulation results may not generalize to performance under actual conditions is substantially weakened by these and parallel results from the analyses of mistaken identifications. 
Laboratory versus field experiment differences in levels of performance are largely accounted for by the different methodologies used in the two settings, which attempt to reflect the natural variations in witnessing and identification conditions that exist in real-world eyewitness situations. Laboratory, field, and real eyewitness situations all vary along dimensions such as attention, load at study and recognition, opportunity to view, same- versus cross-race identifications, and so on. Therefore, knowledge about the effects of these variations on eyewitness performance should, in principle, be of value to all those (police, district attorneys, judges, jurors, and psychologists) trying to evaluate the reliability of an identification made under a particular set of circumstances.

IV

\section{Legal Issues Concerning Expert Testimony}

That mistaken identifications occur is not necessarily troublesome, at least insofar as the identification procedures are fair. After all, the witness does not convict an innocent suspect; guilt or innocence is the province of judge or jury. Nevertheless, because mistaken identifications do occur, the criminal justice system requires the use of corroborative evidence and provides for rigorous cross-examination in order to minimize the probability that a mistaken identification will result in a conviction. From a psychological perspective, however, serious questions can be raised as to the effectiveness of these safeguards.

\section{A. Traditional Safeguards}

The Supreme Court has recognized limitations on the admissibility of eyewitness identification evidence when counsel is absent from the identification proceeding, ${ }^{24}$ when identification procedures are overly suggestive, ${ }^{25}$ and when other evidence surrounding the identification makes the accuracy of the identification unreliable. ${ }^{26}$ While these safeguards are helpful, they may not be adequate to prevent miscarriages of justice associated with mistaken identifications. Consider "other evidence" bearing on the reliability of an identification. The criteria identified by the Supreme Court in Neil $v$. Biggers ${ }^{27}$ as indicators of identification accuracy are only

24. Gilbert v. California, 388 U.S. 263 (1967) (post-indictment identification of accused in lineup inadmissible because accused's attorney was not present); United States v. Wade, 388 U.S. 218 (1967) (criminal defendant has right to counsel at post-indictment lineup proceeding).

25. Stovall v. Denno, 388 U.S. 293, $301-02$ (1967) (unnecessarily suggestive identification procedure is a recognized ground for due process attack) (citing Palmer v. Peyton, 359 F.2d 199 (4th Cir. 1966)).

26. Manson v. Brathwaite, 432 U.S. 98 (1977) (eyewitness identification may be inadmissible if the totality of circumstances casts doubt on the reliability of the identification); Neil v. Biggers, 409 U.S. 188 (1972).

27. 409 U.S. 188, 199-200 (1972). The factors were: the opportunity to view the criminal during the crime, the witness' degree of attention, the accuracy of the witness' prior description, the witness' level of certainty in the identification, and the interval between the crime and the identification. 
partially consistent with the empirical literature. The Court correctly pointed out that factors such as exposure time and retention interval should be taken into consideration when evaluating the accuracy of identifications. ${ }^{28}$ But the Court also pointed to factors such as the accuracy of a witness' prior description of a perpetrator and the level of confidence demonstrated by the witness in the accuracy of the identification. ${ }^{29}$ Later psychological literature raises serious doubts about the correctness of the Supreme Court's assumption that predictive validity is related to the accuracy of the witness' prior description of a perpetrator and to the confidence the witness has in the accuracy of the identification. ${ }^{30}$

It is sometimes argued that cross-examination of the eyewitness also serves as an important safeguard against mistaken identifications. ${ }^{31}$ The duty of the attorney is to make the jury aware of the factors associated with the crime that call the accuracy of the identification into question. If, during the cross-examination, the attorney establishes that the witness, having just left a well lit room, viewed a perpetrator running down a dark corridor, it is then up to the jury to draw the appropriate inference as to the likelihood that the identification of the perpetrator was accurate. But is it reasonable to expect that the jury is competent, without expert testimony, to give appropriate consideration to factors such as dark adaptation and brief exposure time when evaluating the identification? One author suggests that jurors are unlikely to draw these inferences. ${ }^{32}$ Furthermore, this same author contends that even if the attorney were allowed to point to counterintuitive research findings during cross-examination, the jury would probably dismiss the suggestions as conjectural. ${ }^{33}$ Though the author doubts the effectiveness of crossexamination in this regard, whether or not the jury will reach a counterintuitive conclusion on the basis of the attorney's cross-examination is best treated as an empirical question.

As an aid to jury decisionmaking, at least one court has gravitated toward the use of judicial instructions. ${ }^{34}$ Judicial instructions concerning eyewitness testimony should arguably have the effect of reducing reliance on crossexamination and should allow the information contained in the instructions to supplement what can be developed in examination of witnesses. In United States $v$. Telfaire ${ }^{35}$ the District of Columbia Circuit endorsed the use of a cautionary eyewitness instruction in cases where the reliability of the

28. Id.

29. Id.

30. Deffenbacher, Eyewitness Accuracy and Confidence: Can We Infer Anything about Their Relationship?, 4 Law \& Hum. Behav. 243 (1980); Wells \& Murray, What Can Psychology Say about the Neil v. Biggers Criteria for Judging Eyewitness Accuracy?, $68 \mathrm{~J}$. Applied Psychology 347, 350-51, 354 (1983); Wells \& Murray, Eyewitness Confidence, in Eyewitness Testimony, supra note 21 , at 155, 169.

31. See, e.g., Robertson v. McCloskey, 676 F. Supp. 351, 354 (D.D.C. 1988).

32. Comment, Admission of Expert Testimony on Eyewitness Identification, 73 Calif. L. Rev. 1402, 1404-05 (1985).

33. Id. at 1404 .

34. United States v. Telfaire, 469 F.2d 552, 555 (D.C. Cir. 1972).

35. Id. 
identification is at issue. ${ }^{36}$ This instruction directs the attention of the jury to specific factors associated with the crime that might influence the accuracy of an identification, including whether the witness had an adequate opportunity to view the perpetrator, whether the witness ever failed to identify the defendant, and whether the witness was certain about the identification. ${ }^{37}$

Although the Telfaire instruction appears to be a step in the appropriate direction, there are, once again, reasons to believe that the specific instruction will be only minimally effective. First, the instruction points only to certain factors without explaining the relative impact those factors have on memory or identification accuracy. Second, some of the factors to which the Telfaire instruction alludes are of questionable relevance. For example, the Telfaire instruction points to the importance of the "strength of the identification," or the confidence of the eyewitness in the accuracy of the identification. ${ }^{38}$ Unfortunately, psychological research demonstrates that the confidence of the witness is not strongly associated with the accuracy of the identification. ${ }^{39}$

If one agrees that judicial instructions concerning the reliability of an eyewitness identification should be predicated on empirical findings and theoretical models, then one can plausibly argue that such commentary should be given by those most familiar with the research. Thus, expert testimony by psychologists might be more effective than judicial instructions in focusing the jury's attention on those factors most likely to affect the accuracy of an eyewitness identification.

It is critical to note that expert psychological testimony about eyewitness memory is quite different from expert clinical or psychiatric testimony. In the latter, the expert is commonly called upon to give an opinion about the mental state or the credibility of a witness. In the former, the eyewitness expert gives no such opinion. Instead, the eyewitness expert discusses basic memorial processes (for example, the perception, encoding, storage, and retrieval stages of memory, and the constructive nature of memory) and the types of experiments that are conducted on memory (for example, the staged incident paradigm). In addition, the expert typically discusses factors specific to the case that might have influenced the witness' memory (for example, cross-racial identifications or the effects of stress). In this respect, the testimony of the eyewitness expert is more analogous to a cautionary judicial instruction than it is to expert clinical or psychiatric testimony. ${ }^{40}$

\section{B. Developments in the Case Law}

Although the grounds for admitting expert psychological testimony on eyewitness issues seem straightforward, the final decision as to its

36. Id. at 556 .

37. Id. at 558 .

38. Id.

39. Deffenbacher, supra note 30 , at 244-46.

40. Monahan \& Walker, Social Science Research in Law: A New Paradigm, 43 Aм. Psychologist 465, $467,469-70$ (1988). 
admissibility has been left to the discretion of the trial judge. ${ }^{41}$ Until recently, judges in most cases have excluded this type of expert testimony, reasoning that such testimony would usurp the jury's role in assessing the credibility of the eyewitness, and that such information is already within the ken of the jury. ${ }^{42}$

In the first decision of its kind, the Arizona Supreme Court ruled in State v. Chapple ${ }^{43}$ that a trial judge abused his discretion in excluding expert psychological testimony on the reliability of an eyewitness identification. The expert in Chapple was prepared to discuss the effects on memory of unconscious transference and post-event information, the weak relationship between confidence and accuracy, and several other related factors. ${ }^{44}$ Unlike other courts, ${ }^{45}$ the Chapple court, in overturning the defendant's conviction, was unwilling to assume that the jury was aware of such factors and could properly apply them in evaluating the accuracy of an eyewitness identification. ${ }^{46}$

The Chapple decision preceded by several months the decision in People $v$. McDonald ${ }^{47}$ which even more forcefully argued for the admissibility of expert psychological testimony on eyewitness memory. In McDonald, the California Supreme Court ruled that the trial judge had abused his discretion in excluding expert psychological testimony on memory, and stated:

When an eyewitness identification of the defendant is a key element of the prosecution's case but is not substantially corroborated by evidence giving it independent reliability, and the defendant offers qualified expert testimony on specific psychological factors shown by the record that could have affected the accuracy of the identification but are not likely to be fully known to or understood by the jury, it will ordinarily be error to exclude that testimony. ${ }^{48}$

The McDonald court observed:

The expert testimony in question does not seek to take over the jury's task of judging credibility: as explained above, it does not tell the jury that any particular witness is or is not truthful or accurate in his identification of the defendant .... The jurors retain both the power and the duty to judge the credibility and weight of all testimony in the case, as they are told by a standard instruction. ${ }^{49}$

Chapple and McDonald were the first in a series of cases that have taken a favorable view of the admissibility of expert testimony on eyewitness

41. See Commonwealth v. Francis, 390 Mass. 89, 453 N.E.2d 1204 (1983), and cases cited therein

42. United States v. Fosher, 590 F.2d 381 (1st Cir. 1979); United States v. Brown, 540 F.2d 1048 (10th Cir. 1976); United States v. Amaral, 488 F.2d 1148 (9th Cir. 1973); People v. Johnson, 38 Cal. App. 3d 1, 112 Cal. Rptr. 834 (1974); Jones v. State, 232 Ga. 762, 208 S.E.2d 850 (1974); State v. Ammons, 208 Neb. 812, 305 N.W.2d 812 (1981).

43. 135 Ariz. 281,660 P.2d 1208 (1983).

44. Id. at 293-94, 660 P.2d at $1220-21$.

45. See, e.g., United States v. Amaral, 488 F.2d 1148 (9th Cir. 1973) (the court of appeals implicitly assumed that jurors were capable of properly assessing the accuracy of an eyewitness identification without benefit of expert testimony).

46. Chapple, 135 Ariz. at 294, 660 P.2d at 1221.

47. 37 Cal. 3d 351, 690 P.2d 709, 208 Cal. Rptr. 236 (1984).

48. Id at 377, 690 P.2d at 727, 208 Cal. Rptr. at 254.

49. Id. at 370-7I, 690 P.2d at 722, 208 Cal. Rptr. at 249. 
memory. ${ }^{50}$ Yet neither court established adequate criteria for other courts to use in deciding whether to allow this type of expert testimony.

\section{V \\ Jurop Sensitivity to Eyewitness Evidence}

A. Dimensions and Importance of Juror Sensitivity

A central tenet underlying the developing legal position on expert psychological testimony is that jurors are not fully aware of scientific knowledge about memory processes. It is assumed that jurors are not fully sensitive to the factors that influence eyewitness memory. Sensitivity, in this context, may refer to: (1) the knowledge of how a factor influences memory and (2) the ability to integrate or use that knowledge when making an inference or judgment about eyewitness accuracy. If jurors are not adequately sensitive to factors that influence the accuracy of eyewitness identifications, they cannot effectively evaluate eyewitness evidence. Such insensitivity raises doubts about the effectiveness of traditional safeguards designed to protect defendants from mistaken identifications.

\section{B. Prior Research}

Do lay people effectively use identification evidence to draw appropriate inferences about the accuracy of identifications? A few studies have addressed this question. These studies generally use one of three methodologies: ${ }^{51}$ a multiple-choice questionnaire in which lay people are queried about factors that influence eyewitness memory, ${ }^{52}$ a prediction method in which the witnessing conditions of an eyewitness experiment are described to the subject and the subject predicts the identification accuracy rates, ${ }^{53}$ and a mock-jury method in which jurors try a case involving eyewitness evidence. ${ }^{54}$ While each methodology has its advantages and disadvantages, studies employing these designs have generally concluded that their empirical findings are often inconsistent with lay knowledge of, and assumptions about, factors that influence eyewitness identification accuracy-particularly with respect to eyewitness confidence. These findings have led Wells to

50. United States v. Sebetich, 776 F.2d 412 (3d Cir. 1985); United States v. Downing, 753 F.2d 1224 (3d Cir. 1985); United States v. Smith, 736 F.2d 1103 (6th Cir.) (per curiam), cert. denied, 469 U.S. 868 (1984); State v. Buell, 22 Ohio St. 3d 124, 489 N.E.2d 795 (1986).

51. For a critical review of these methods, see Wells, How Adequate Is Human Intuition for Judging Eyewitness Testimony?, in Eyewitness Testimony, supra note 21 , at 256.

52. See Deffenbacher \& Loftus, Do Jurors Share a Common Understanding Concerning Eyewitness Behavior?, 6 LAw \& HuM. Behav. 15, 18, 26-29 (1982); Yarmey \& Jones, Accuracy of Memory of Male and Female Eyewitnesses to a Criminal Assault and Rape, 21 Bull. Psychonomic Soc'y 89, 90 (1983).

53. Brigham \& Bothwell, The Ability of Prospective Jurors to Estimate the Accuracy of Eyewitness Identifications, 7 LAW \& HuM. BeHAV. 19, 22-24 (1983).

54. See Lindsay, Wells \& Rumpel, Can People Detect Eyewitness-Identification Accuracy Within and Across Situations?, $66 \mathrm{~J}$. APPlied Psychology 79, 82-83 (1981); Wells, Ferguson \& Lindsay, The Tractability of Eyewitness Confidence and Its Implications for Triers of Fact, $66 \mathrm{~J}$. APPLIED PsycholoGy 688 , 690-91 (1981). 
recommend that "the lay person, as trier of fact, be counseled on these matters." 55

Although previous research is consistent in showing that lay knowledge is often at odds with experimental findings, the implications of these findings are unclear. First, there is reason to believe that some of the previous research may have overestimated lay knowledge of the factors that influence eyewitness memory. Questionnaire studies, for example, provide respondents with multiple-choice items-items chosen by the investigator because of their supposed pertinence to eyewitness memory. Thus, the mere presence of an item on a test (for example, an item about cross-race versus same-race recognition) might sensitize the respondent to the importance of the factor. It is not clear whether pertinent witnessing or identification factors would be as salient in a criminal trial as they are in the surveys. The problem is one of external validity, that is, the extent to which laboratory findings apply to the real world. ${ }^{56}$ It is also questionable whether the cognitive processes associated with demonstrating one's knowledge through responses to a psychological survey generalizes to drawing inferences about criminal behavior from evidence presented at trial. For these reasons, we place more emphasis on mock-jury studies than on questionnaire studies.

The prediction method can also be validly criticized because it is questionable whether a description of an experiment captures the essential elements of the actual experiment. If it does not, there is little reason to expect that subjects will accurately estimate eyewitness performance in the experiment.

Previous mock-jury studies might also overestimate the impact of witnessing and identification factors on jurors' inferences. The underlying basis for this claim is that previous mock-jury studies rarely manipulated more than one or two variables in the body of trial evidence. The manipulated factors, therefore, can theoretically account for a very large portion of the variability in jurors' decisions. This contention is exemplified by Wells, Lindsay, and Ferguson's finding ${ }^{57}$ that witness confidence accounted for fully 50 percent of the variability in jurors' belief in the witness testimony. That is, jurors' beliefs about witness accuracy were substantially determined by the confidence expressed by the witness. In an actual trial, the jurors' decisions are multiply determined, and the number of determinants of a decision (for example, jurors' inferences) is, logically, inversely related to the predictive value of any one factor.

In summary, previous research indicates that lay persons' notions about witnessing factors, such as witness confidence, are inconsistent with the

55. Wells, supra note 51 , at 272

56. See, e.g., Berkowitz \& Donnerstein, External Validity Is More Than Skin Deep: Some Answers to Criticisms of Laboratory Experiments, 37 AM. Psychologist 245 (1982); Ebbesen \& Konecni, On the External Validity of Decision-Making Research: What Do We Know about Decisions in the Real World?, in Cognitive Processes in Choice and Decision Behavior 21 (T. Wallsten ed. 1980).

57. Wells, Lindsay \& Ferguson, Accuracy, Confidence, and Juror Perceptions in Eyewitness Identification. 64 J. Applied Psychology 440 (1979). 
findings reported in the literature. Even though previous research yields consistent findings, there are sound reasons to believe that the extent of the impact of eyewitnessing factors on jurors' inferences can be better estimated by simultaneously examining the effects of multiple witnessing factors, and by more closely approximating actual criminal cases, that is, by increasing the external validity of the experiment. The need for such an approach is succinctly stated by Woocher: "Attempts should be made, wherever possible, to simulate real-life conditions in psychological research ... so that the expert's testimony based on these experiments cannot be criticized as too far removed from reality to bear any relevance to the court proceedings." 58

\section{Assessing Juror Sensitivity to Eyewitness Evidence}

In a series of studies, ${ }^{59}$ we have investigated jurors' use of eyewitness evidence. These experiments examined the lay person's knowledge about and critical consideration of the variables that influence eyewitness memory, and the lay person's belief in or skepticism about the accuracy of eyewitness memory.

1. The Jurors and the Trial. Subjects in the first two studies viewed a videotaped trial of a defendant accused of the armed robbery of a liquor store. ${ }^{60}$ Subjects in the first study were 321 undergraduates who received course credit for participation as mock jurors. The second study employed the same design, but the subjects were 129 jury-eligible and experienced jurors. Each juror was paid ten dollars for participating in the experiment. Subjects watched the videotaped trial and completed a thirty-three item questionnaire containing the primary dependent measures and the manipulation checks. The videotaped trial lasted approximately forty-five minutes. The format of the trial followed that of an actual trial. It began with the prosecution's opening statement and was followed by the defense's opening statement, examination and cross-examination of the four witnesses, the prosecution's closing argument, and the defense's closing argument. The videotape concluded with standard instructions from the judge. During their closing arguments, both attorneys reiterated and emphasized all the conditions surrounding the crime and the identification procedures manipulated in the experiment. To maximize the realism of the videotaped trial, practicing trial attorneys assumed the roles of attorneys.

58. Woocher, supra note 14 , at 60 .

59. Cutler, Dexter \& Penrod, Expert Testimony and Jury Decision Making: An Empirical Analysis, 7 Behav. Sci. \& Law 215 (1989); Cutler, Penrod \& Dexter, The Eyewitness, the Expert Psychologist, and the Jury, 13 Law \& Hum. Behav. 311 (1989); Cutler, Penrod \& Dexter, Juror Sensitivity to Eyeuitness Identification Evidence, 14 Law \& Hum. Behav. 185 (1990); Cutler, Penrod \& Dexter, Non-Aḋersarial Methods for Improving Juror Sensitivity to Eyewitness Evidence (in press, J. APPled Soc. Psychology); Cutler, Penrod \& Stuve, Juror Decisionmaking in Eyewitness Identification Cases, 12 Law \& Hum. Berav. 41 (1988); Cutler, Penrod \& Dexter, Expert Testimony on Eyewitness Identification: The Hired Gun, the Friend of the Court, the Battling Experts, and the Judge (unpublished paper under review).

60. See supra citations at note 59 and accompanying text. 
The primary source of evidence in the trial was the positive identification of the defendant by the robbery victim. In all, four witnesses (the first two for the prosecution and the second two for the defense) were examined and cross-examined. The first witness was the liquor store clerk who was the victim of the robbery. She testified about the witnessing conditions at the time of the robbery, and the conditions under which she identified the defendant as the robber. The second witness was the police officer in charge of the investigation. He also testified about the conditions under which the identification was made. The third witness was a friend of the defendant who served as a character witness and offered a relatively weak alibi for the defendant. The fourth witness was the defendant. He denied all allegations against him, but offered little concrete evidence in support of his innocence.

2. Independent Variables. Approximately twenty witnessing and identification factors were discussed in the trial, all of which surfaced in the examination and cross-examination of the first two witnesses. Ten of these variables were systematically manipulated in a complex design that yielded sixty-four factually different versions of the trial. ${ }^{61}$ Each factor was presented in one of two forms. The ten factors were:

1. Disguise. In half of the videotapes, the witness testified that the robber wore a knit cap fully covering his hair during the robbery. In the other half of the videotapes, the witness testified that the robber wore no hat.

2. Weapon presence. The witness testified either that the robber outwardly brandished a handgun and pointed it at her throughout the robbery or that the weapon was concealed. This manipulation was designed to test for a "weapon focus" effect. ${ }^{62}$

3. Violence. In 50 percent of the cases, the witness testified that the robber verbally threatened to kill her, manhandled her, fired his handgun into the floor, and pushed her to the floor before leaving; in the remaining cases, the witness testified that the robber calmly and quietly demanded the money, and left after the clerk complied with the robber's demands.

4. Retention interval. The witness testified that the identification was made either two or fourteen days after the robbery.

5. Mugshot search. The witness testified that during the interval between the robbery and the identification, she either searched or did not search through mugshot books for the robber.

6. Lineup instructions. In all of the videotapes, the police officer repeated verbatim the instructions given to the witness before the

61. See Kenny, Quantitative Methods for Social Psychology, in 1 The Handbook of Social Psychology 487, 490 (G. Lindzey \& E. Aronson eds. 1985).

62. See Cutler, Penrod \& Martens, The Reliability of Eyewitness Identifications: The Role of System and Estimator Variables, 11 LAW \& Hum. BEHAv. 233, 240 (1987); Loftus, Silence Is Not Golden. 38 Am. Psychologist 564, 568, 569 (1983). 
witness made a decision on the lineup test. In half of the videotapes, the police officer instructed her to "choose the suspect from the lineup whom you believe is the robber or indicate that the robber is not in the lineup." In the other half, the police officer instructed her to "choose the suspect from the lineup whom you believe is the robber," without explicitly offering her the option of rejecting the lineup.

7. Lineup size. The witness testified that there were either six or twelve persons in the lineup from which the defendant was identified.

8. Similarity of lineup members. This manipulation refers to the fairness of the lineup. ${ }^{63}$ In half of the trials, the witness testified that there were several lineup members who resembled the robber in physical appearance. The police officer also testified that, in choosing foils to appear in the lineup, he provided another officer (not involved with the case) with the witness' original description of the robber and asked him to choose foils for the lineup who matched that description. In the other half of the videotapes, the witness testified that there were few lineup members who resembled the robber in physical appearance and the officer testified that, in choosing foils for the lineup, he recruited anyone who was available at the time.

9. Voice samples. The witness testified either that she was allowed to hear the lineup members speak before making a decision or that she did not hear the lineup members speak.

10. Witness confidence. The witness testified that she was either 80 percent or 100 percent confident that she had correctly identified the robber.

Testimony was also given about additional factors, but these factors were held constant across experimental conditions. For example, the witness testified that she was able to view the robber for approximately 90 seconds (the duration of the robbery), and that before seeing the lineup, she was about 80 percent confident that she could correctly identify the robber. In addition, the witness testified that she was allowed to see a front, three-quarter, and full profile view of each person in the lineup parade. The defendant testified that he had no prior convictions.

The manipulated variables were chosen because of their forensic relevance and because they have been shown to have reliable effects on identification accuracy (although some of the variables show more reliable effects than

63. Doob \& Kirshenbaum, Bias in Police Lineups-Partial Remembering, 1 J. Police Sci. \& Admin. 287, 289 (1973); Lindsay \& Wells, What Price Justice? Exploring the Relationship of Lineup Faimess to Identification Accuracy, 4 LAw \& Hum. Behav. 303 (1980); Malpass \& Devine, Measuring the Fairmess of Eyewitness Identification Lineups, in Evaluating Witness Evidence (S. Lloyd-Bostock \& B. Clifford eds. 1983). 
others). ${ }^{64}$ For example, a recent analysis of thirty-five tests of the eyewitness confidence-accuracy relationship found the average correlation to be .25 .65

Examining the witnessing and identification variables together with witness confidence allowed us to verify an earlier finding that if the witness was highly confident, jurors failed to take into consideration other witnessing information (that is, exposure time and disguise of the robber) when inferring the accuracy of the identification. ${ }^{66}$ However, if the witness was less confident, jurors did take the witnessing conditions into consideration when inferring the accuracy of the identification. In these studies, this effect would emerge as statistical interactions between witnessing (or identification) factors and witness confidence in the prediction of jurors' inferences and judgments.

3. Dependent Variables. The two primary dependent variables measured in the study were verdict (guilty or not guilty) and each subject's rating of the probability that the identification was correct. Other dependent variables included the strength of each side's case, the credibility of each of the four witnesses, the fairness of the lineup procedures, the neutrality of the lineup instructions, and how threatened and frightened the witness testified to having been during the robbery. In addition, subjects rated the probability that the average person could make a correct identification given the circumstances described. A set of free recall questions tested subjects, memories for the testimony and eyewitnessing conditions.

4. Results. Results indicated first that jurors remembered the evidence quite well. In particular, recall of the witnessing conditions was generally over 90 percent accurate. However, despite the excellent recall, none of the variations in eyewitnessing conditions had a significant effect on student jurors' verdicts, on the accuracy of the eyewitness identification, or on the other assessments (dependent variables) they were asked to make. Overall, only witness confidence influenced verdicts-51 percent of the 450 jurors convicted if the eyewitness was 100 percent confident and 37 percent convicted when the witness was 80 percent confident. Estimates of the probability that the identification was correct were 67 percent and 60 percent, respectively.

64. See Brown, Deffenbacher \& Sturgill, Memory for Faces and the Circumstances of Encounter, $62 \mathrm{~J}$. ApPlied Psychology 311 (1977); Buckhout, Eyewitness Testimony, SCI. Am., Dec. 1974, at 23; Buckhout, Alper, Chern, Silverberg \& Slomovits, Determinants of Eyewitness Performance on a Lineup, 4 Bull. Psychonomic Soc'y 191 (1974); Buckhout, Figueroa \& Hoff, Eyewitness Identification: Effects of Suggestion and Bias in Identification from Photographs, 6 Bull. Psychonomic Soc'y 71 (1975); Cutler, Penrod, O'Rourke \& Martens, Unconfounding the Effects of Contextual Cues on Eyewitness Identification Accuracy, I Social Behav. 113, 114, 120, 126 (1986); Davies, Shepherd \& Ellis, Effects of Interpolated Mugshot Exposure on Accuracy of Eyewitness Identification, 64 J. APPLIED Psychology 232 (1979); Deffenbacher, The Influence of Arousal on Reliability of Testimony, in Evaluating WITNESS EvidencE, supra note 63; Malpass \& Devine, Eyewitness Identification: Lineup Instructions and the Absence of the Offender, 66 J. Applied Psychology 482 (1981); Shapiro \& Penrod, supra note 22.

65. Bothwell, Deffenbacher \& Brigham, Correlation of Eyewitness Accuracy and Confidence: Optimality Hypothesis Revisited, 72 J. Applied Psycholocy 691 (1987).

66. Lindsay, Wells \& Rumpel, supra note 54 , at 84. 
Notably, among experienced jurors, but not among the students, weapon presence did have an appreciable effect on probability ratings and on verdicts, with the former being statistically significant. This effect, though, was contrary to empirical findings. These jurors were more likely to find the identification correct (66 percent) and to convict (46 percent) when the weapon was present than when the weapon was hidden (54 percent and 30 percent, respectively).

Another analysis addressed the "witness sensitivity" hypothesis. This hypothesis is based on the notion that jurors may assume that the eyewitness was influenced by and/or accounted for witnessing and identification factors when assessing her confidence in the accuracy of the identification. If that were the case, jurors might see no reason to weigh these factors independently and instead might rely solely on the witness' assessment of these factors. Do jurors assume that witness confidence is influenced by such factors?

To investigate this question, the study analyzed subjects' estimates of the probability that the "average person" could make a correct identification under the same circumstances in which the eyewitness identification was made. This question asks jurors to ignore the idiosyncratic verbal and nonverbal confidence information attributable to the specific witness in the videotape. If the "witness sensitivity" hypothesis is true, the high or low confidence expressed by the witness should have no effect on jurors" inferences about the probability that the average person could make a correct identification given the circumstances. However, other witnessing factors might affect jurors' inferences.

Witness confidence, as expected, had a statistically insignificant effect on probability ratings. However, none of the other variables affected probability ratings either! This finding indicates that subjects could disregard the specific witness' confidence when drawing inferences about the average person's ability to make a correct identification, but did not compensate by differentially weighing the other witnessing and identification factors. The hypothesis that jurors fail to weigh witnessing and identification factors and instead assume that the witness has done so in establishing confidence level was therefore not supported by the results.

An analysis of the combined student and juror data set was undertaken to determine whether general belief levels in eyewitness identification or sensitivity to eyewitness evidence varied across subject groups. The results clearly demonstrated that the sample is insensitive to virtually all of the eyewitness identification evidence. Other than witness confidence, no single variable produced a substantial or statistically significant effect on judgments. Furthermore, the two groups did not differ significantly in their overall verdicts and evidence ratings.

Only two differences in the use of witnessing factors emerged: Jurors were significantly more sensitive to the mugshot testimony than were the undergraduates, and jurors placed significantly more weight on the weapon 
presence testimony than did the undergraduates. The effect of weapon presence on the jurors' judgments does not reflect sensitivity, as the direction is opposite to that reported in the eyewitness literature. Both undergraduates and eligible jurors placed about the same (disproportionate) weight on witness confidence. ${ }^{67}$

\section{Implications}

Although these experiments represent a substantial step toward establishing the greater applicability of laboratory results to real-world situations, they still support the conclusion of previous, less externally valid research. Of the ten factors that were manipulated, only witness confidence had a statistically significant effect on verdicts and on the perceived probability that the identification was correct. The finding that witness confidence predicted verdict and probability ratings was expected, given previous similar findings. ${ }^{68}$ Thus, the present study strongly suggests that, relative to the other eyewitnessing factors that had trivial effects on jurors' inferences, jurors weigh witness confidence disproportionately.

The factors that have been shown to affect identification accuracy (disguise of robber, weapon focus, violence of robbery, retention interval, exposure to mugshots, biased lineup instructions, lineup size, and fairness of the lineup) had negligible effects on probability ratings and on verdicts. It is crucial to note that, in our manipulation checks, subjects demonstrated superior memory for evidence about disguise, weapon visibility, retention interval, exposure to mugshots, and lineup size. In addition, violence of the crime, biased lineup instructions, and lineup fairness all had profound effects on the inferential rating scales, as evidenced by the effect size index $d^{69}$ There is little doubt that subjects attended to and understood this evidence during the trial, but they did not use the information to draw inferences about the accuracy of the identification, culpability of the defendant, strength of the prosecution's and defense's case, or credibility of the witness. Thus, there was no evidence to support the proposition that jurors take witnessing factors into consideration if the witness is less confident, but do not if the witness is highly confident.

During the closing arguments of the videotaped trials, the attorneys emphasized the conditions surrounding the crime and, in particular, the manipulaced identification factors. For example, instead of pointing out that there was only one witness to the crime and the other evidence was weak, the defense attorney instructed the jury to consider (in the appropriate circumstances) that the robber was disguised, that the witness was under considerable stress during the crime, that the lineup instructions pressured the witness to make an identification, and that the lineup was unfair. Thus, the attorneys gave more attention to these factors than they might have

67. See supra citations at note 59 and accompanying text.

68. Lindsay, Wells \& Rumpel, supra note 54; Wells, Lindsay \& Ferguson, supra note 57, at 446.

69. See supra Part III.B for a discussion of effect size $d$. 
normally. This extra emphasis might be expected to sensitize the jurors to the factors surrounding the identification. Apparently it did not.

These studies clearly indicate that jurors are insensitive to eyewitness evidence and that, with few exceptions, undergraduates and eligible jurors are equally insensitive. When evaluating the identification, both groups were insensitive to the effects of disguise, weapon presence, retention interval, suggestive lineup instructions, and procedures used for constructing and carrying out the lineup; both groups gave disproportionate weight to the confidence of the witness.

These results also speak to the real-world validity of mock-jury research. As previously noted, several researchers have criticized the validity of eyewitness research on the basis of its predominant use of the undergraduate population. ${ }^{70}$ The evidence from these studies indicates that eligible jurors gave judgments similar to those of the undergraduates, thus supporting the notion that research using undergraduates is, at least under some circumstances, generalizable to the larger population of eligible jurors.

\section{VI}

\section{Plausible Effects of Expert's Influence on the Jury}

Commentators have offered a variety of hypotheses about the effects that expert testimony on eyewitness issues may have on jurors. ${ }^{71}$ These hypotheses can generally be classified into three categories: juror sensitivity, juror confusion, and juror skepticism.

\section{A. Juror Sensitivity: Knowledge and Integration}

Proponents of the use of expert psychological testimony on eyewitness accuracy argue that such testimony would serve precisely the function envisioned in Rule 702 of the Federal Rules of Evidence in that it "will assist the trier of fact to understand the evidence or to determine a fact in issue . . ."72 In light of the earlier discussion of research showing that jurors appear to be insensitive to probative evidence concerning the impact of eyewitnessing factors on eyewitness performance, this hypothesis suggests that expert testimony will sensitize jurors to the effects of various factors on eyewitness performance and enable them to evaluate evidence more effectively. Increased juror sensitivity to witnessing factors clearly would be a desirable effect. ${ }^{73}$

Note that sensitivity has two components: knowledge and integration. Knowledge refers to simple awareness of how a factor influences eyewitness memory, such as the direction and magnitude of the effect for a given factor. Integration refers to the ability to render decisions that reflect knowledge.

70. E.g., Konecni \& Ebbesen, supra note 15, at 123-24.

71. For a review of the available research, see Wells, supra note 51.

72. FED. R. Evid. 702 (1975).

73. McCloskey, Egeth \& McKenna, supra note 15; Wells, supra note 51. 
For example, a judge of a pageant might specify in advance that candidates shall be rated on the dimensions of physical beauty, personality, and entertainment skills and that these three factors shall be given equal weight. Though specified a priori, there is no guarantee that the judge's ratings will actually reflect this weighting scheme. A perusal of a collection of data might indicate that entertainment skills were given substantially less weight than personality, which, in turn, was given less weight than physical beauty. If this were so, the judge would show poor integration skills. If, on the other hand, a collection of judgments indicated that the judge in fact used the rating scale in accordance with the a priori rating scheme, the judge would show good integration skills.

We have already seen that jurors are unaware of how some factors influence eyewitness memory. But even if jurors were aware of the relative effects of a given factor on eyewitness memory, the impact of that factor might be attenuated due to jurors' poor integration or evaluation of the evidence. In other words, the jurors' judgments might not reflect their a priori knowledge. Decisionmaking research in a variety of psychological domains shows that integration is quite difficult to achieve, even with trained judges. ${ }^{74}$

\section{B. Juror Confusion}

Critics of eyewitness expert testimony follow the analysis of Rule 403 of the Federal Rules of Evidence and argue that expert testimony will either have no effect on jurors and will therefore be a waste of time, or that the testimony will simply confuse jurors and make it difficult for them to sort out and evaluate the evidence. ${ }^{75}$ Some psychologists have expressed similar reservations about expert testimony, stating that "there is the possibility that the testimony will affect the jury in some unanticipated and undesirable way. Jurors may misinterpret, overgeneralize, or misapply the information presented by the psychologist, and so may come to unwarranted conclusions." 76

Clearly, it is possible that expert testimony will have no effect on the judgments of jurors. Though pessimistic, this hypothesis is reasonable in light of research indicating that jurors have difficulty understanding and applying legal concepts at many stages of the trial process. At the pretrial stage, it has been amply documented that judicial admonitions to ignore pretrial publicity when drawing inferences about a defendant are largely

74. See, e.g.. Goldberg, Simple Models or Simple Processes? Some Research on Clinical Judgments, 23 AM. Psychologist 483 (1968); Slovic, Analyzing the Expert Judge: A Descriptive Study of a Stockbroker's Decision Processes, 53 J. Applied Psychology 255 (1969) (technique based on the analysis of variance employed to describe stockbroker's evaluation of a security).

75. McCloskey, Egeth \& McKenna, supra note 15, at 6.

76. Id. 
ineffective. ${ }^{77}$ The procedures used to select juries can lead the jurors to draw inferences about a defendant's guilt. ${ }^{78}$

Jurors' understanding of various forms of trial evidence has been the focus of considerable research. Thompson and Schumann ${ }^{79}$ have shown that jurors have difficulty evaluating mathematical and statistical evidence. Jurors also are known to draw inappropriate inferences in trials in which multiple loosely related charges against a defendant are joined. ${ }^{80}$ The studies reported above clearly document the difficulty that jurors have with eyewitness identification evidence.

Instructions given to the jury at the conclusion of the trial typically contain healthy doses of legal jargon and clearly pose a challenge to jurors' interpretive skills. Jurors have been shown to have difficulty with the most common types of pattern instructions ${ }^{81}$ and standards of proof. ${ }^{82}$ In addition, jurors have difficulty applying more specialized instructions such as those involving confessions ${ }^{83}$ and presumptions. ${ }^{84}$

In short, there is abundant evidence that jurors have difficulty understanding some trial evidence and sometimes have difficulty conforming their decisions to the instructions they receive. The research underscores the plausibility of the assertion that expert testimony will have little effect on the

77. See, e.g., Kline \& Jess, Prejudicial Publicity: Its Effect on Law School Mock Juries, 43 Journatism Q. 113 (1966); Sue, Smith \& Gilbert, Biasing Effects of Pretrial Publicity on Judicial Decisions, 2 J. CRIM. Just. 163 (1974); Sue, Smith \& Pedroza, Authorilarianism, Pretrial Publicity, and Awareness of Bias in Simulated Jurors, 37 Psychological ReP. 1299 (1975).

78. Haney, Examining Death Qualification, 8 Law \& Hum. BeHav. 133 (1984); Haney, On the Selection of Capital Juries: The Biasing Effects of the Death Qualification Process, 8 LAw \& Hum. Benav. 121 (1984).

79. Thompson \& Schumann, Interpretation of Statistical Evidence in Criminal Trials: The Prosecutor's Fallacy and the Defense Attorney's Fallacy, 11 LAW \& HuM. BEHAv. 167 (1987).

80. Greene \& Loftus, When Crimes Are Joined at Trial, 9 LAw \& Hum. Behav. 193 (1985); Horowitz, Bordens \& Feldman, $A$ Comparison of Verdicts Obtained in Severed and Joined Criminal Trials, $10 \mathrm{~J}$. APPLIED Soc. Psychology 444 (1980); Tanford \& Penrod, Biases in Trials Involving Defendants Charged with Multiple Offenses, 12 J. Applied Soc. Psychology 453 (1982); Tanford \& Penrod, Social Inference Processes in Juror Judgments of Multiple-Offense Trials, 47 J. Personality \& Soc. Psychology 749 (1984); Tanford, Penrod \& Collins, Decision Making in Joined Criminal Trials: The Influence of Charge Similarity, Evidence Similarity, and Limiting Instructions, 9 LAw \& Hum. Behav. 319 (1985).

81. Charrow \& Charrow, Making Legal Language Understandable: A Psycholinguistic Study of Jury Instructions, 79 Colum. L. Rev. 1306 (1979); Heuer \& Penrod, Increasing Jurors' Participation in Trials: A Field Experiment with Jury Notetaking and Question Asking, 12 LAw \& HuM. BeHav. 231 (1988); Heuer \& Penrod, Instructing Jurors: A Field Experiment with Written and Preliminary Instructions, 13 LAW \& HuM. Behav. 409 (1989); Penrod \& Cutler, Assessing the Competency of Juries, in The Handbook of ForensiC Psychology (I. Weiner \& A. Hess eds. 1987); Severance \& Loftus, Improving the Ability of Jurors to Comprehend and Apply Criminal Jury Instructions, 17 LAw \& Soc'y REv. 153 (1982); Penrod, Conducting Experimental Research with Real Trials (Oct. 1984) (talk given at the Society for Experimental Social Psychology, Salt Lake City).

82. Kagehiro \& Stanton, Legal vs. Quantified Definitions of Standards of Proof, 9 LAW \& HUM. BEHAV. 159 (1985).

83. Kassin \& Wrightsman, Confession Evidence, in The Psychology of Evidence and Trial Procedure (S. Kassin \& L. Wrightsman eds. 1985); Kassin \& Wrightsman, Coerced Confessions, Judicial Instruction, and Mock Juror Verdicts, $11 \mathrm{~J}$. Applied Soc. Psycholocy 489 (1981); Kassin \& Wrightsman, Prior Confessions and Mock Juror Verdicts, $10 \mathrm{~J}$. ApPlied Soc. Psychology 133 (1980).

84. Cutler, Penrod \& Schmolesky, Presumption Instructions and Juror Decision Making, 1 ForensIC REP. 165 (1988). 
judgments of jurors. ${ }^{85}$ While it might be hypothesized further that failure to remember eyewitness evidence or expert testimony might cause this result, the studies discussed earlier demonstrate that memory for eyewitness evidence is quite good.

\section{Juror Skepticism}

Critics of eyewitness expert testimony also cite Rule 403 of the Federal Rules of Evidence to argue that expert testimony may be prejudicial because it will simply induce skepticism about eyewitness testimony generally. ${ }^{86}$ Specifically, these critics contend that the expert psychological testimony will cause jurors to give insufficient and therefore inappropriate weight to actual eyewitness testimony. Legal commentators such as Woocher have observed that "an experimental psychologist's impressive credentials might lead the jury to rely too heavily on her opinion and therefore undervalue the weight of the eyewitness evidence." 87

While there is agreement that improved juror sensitivity is a desirable effect of expert testimony, ${ }^{88}$ there is considerable disagreement about whether jurors should be made more skeptical of the accuracy of eyewitness identifications. ${ }^{89}$ There is ample evidence that eyewitness identifications are often inaccurate. Realistic field experiments show that witnesses give correct judgments on identification tests approximately 50 percent of the time. ${ }^{90}$ But there is less evidence about jurors' a priori beliefs regarding the accuracy of identifications. Given these valid criticisms of the research, few conclusions can be reached about the desirability of a skepticism effect.

\section{Research on Expert Psychological Testimony}

It is theoretically possible to examine skepticism and sensitization effects independently. It is possible to detect juror confusion as well. Unfortunately, the procedures designed to test the effects of expert testimony in previous research have confounded skepticism and sensitization effects and thus made it quite difficult to determine exactly how jurors are affected by expert testimony.

85. McCloskey \& Egeth, supra note 13, at 558 (“"T The available evidence fails to demonstrate that expert psychological testimony will routinely improve jurors' ability to evaluate eyewitness testimony. However, neither do the data rule out the possibility that expert testimony could have beneficial effects."); see also McCloskey, Egeth \& McKenna, supra note 15, at 6-7.

86. McCloskey, Egeth \& McKenna, supra note 15, at 7.

87. Woocher, supra note 14, at 57.

88. McCloskey, Egeth \& McKenna, supra note 15 (an overview of research and scholarly opinions regarding expert psychological testimony): Wells, supra note 51 (discussing desirable versus undesirable effects of expert testimony on jury decisionmaking).

89. Bermant, supra note 14; McCloskey, Egeth \& McKenna, supra note 15. at 7.

90. Brigham, Maass, Snyder \& Spaulding, Accuracy of Eyeuitness Identifications in a Field Setting, $42 \mathrm{~J}$. Personality \& Soc. Psychology 673 (1982); Krafka \& Penrod, Reinstatement of Context in a Field Experiment on Eyeuithess Idenification, 49 J. Personality \& Soc. Psychology 58, Fig. 1 (1985). 
Wells, Lindsay, and Tousignant ${ }^{91}$ showed their subjects videotaped direct examinations and cross-examinations of eyewitnesses (in total, videotapes of 108 different witnesses were used). Half of the subject-jurors also saw videotaped expert testimony about eyewitness testimony. The expert's testimony, which lasted for approximately 5.5 minutes, centered on levels of accuracy of eyewitness identifications and on the weak relationship between confidence and identification accuracy. Finally, the expert suggested that jurors attend to the situational factors involved in the crime and not to the confidence of the witness. Those subjects who heard expert testimony viewed the videotape of the witness cross-examination after the videotape of the expert testimony.

Based on an earlier experiment, ${ }^{92}$ witnesses were classified into one of three groups differing in identification accuracy rates: poor (33 percent correct), moderate (50 percent correct), and good (74 percent correct). The study found a main effect for expert testimony: Jurors who heard expert testimony were less likely to believe the eyewitnesses than jurors who heard no expert testimony. There was also a main effect for witnessing conditions indicating that jurors were somewhat sensitive to them. Although there was a trend toward improved sensitivity with expert testimony, the effect was not statistically significant. Thus the study yielded a skepticism effect and a nonsignificant sensitizing effect.

Loftus'93 mock-jury study subjects read a criminal trial transcript. The violence of the crime and the presence of expert psychological testimony were independently manipulated. Loftus found that expert testimony significantly reduced the number of convictions and that, in direct contradiction to the eyewitness research findings discussed above, the violence of the crime increased the number of convictions. ${ }^{94}$ The trend toward increased convictions associated with violent crime was weakened by the expert testimony, though the effect was not tested for statistical significance. ${ }^{95}$ These findings suggest that the expert testimony produced some sensitization. A second experiment revealed that juries exposed to expert testimony spent significantly more time deliberating about the eyewitness evidence than did juries that were not exposed to expert testimony. ${ }^{96}$

Hosch, Beck, and McIntyre ${ }^{97}$ exposed subjects to a videotaped trial and manipulated the presence of expert testimony. Juries that heard the expert testimony rated the identification as significantly less important to reaching a verdict than did juries that did not hear expert testimony. Expert testimony

91. Wells, Lindsay \& Tousignant, Effects of Expert Psychological Adrice on Human Performance in Judging the Validity of Eyewitness Testimony, 4 Law \& Hum. Beнav. 275 (1980).

92. Lindsay, Wells \& Rumpel, supra note 54.

93. Loftus, Impact of Expert Psychological Testimony on the Linreliability of Eyewitness Identification. $65 \mathrm{~J}$. Applied Psychology 9 (1980).

94. Id. at 12.

95. Id. at 13

96. Id. at $13-14$.

97. Hosch, Beck \& McIntyre, Influence of Expert Testimony Regarding Eyeuitness Accuracy on Jury Decisions, 4 LaW \& Hum. Behav. 287 (1980). 
also significantly increased the amount of time that jurors spent discussing the eyewitness evidence.

Maass, Brigham, and West ${ }^{98}$ examined the impact of several forms of expert testimony on jurors' perceptions of the defendant's guilt. Subjects read one of two court cases describing similar crimes. In both cases, the eyewitness gave a description of the perpetrator to an officer, but in only one case was the perpetrator identified from a lineup parade by the witness. Four expert testimony conditions were formed by combining two factors. Expert testimony relied either on interviews with the witness or on research findings. In addition, the expert either offered an opinion on the probability that the identification was correct and explanations for the probability (for example, time delays, arousal, cross-racial identification), or offered the probability but gave no explanation.

Expert testimony led to more lenient pre- and post-deliberation judgments. ${ }^{99}$ In addition, when the expert testimony was based primarily on interviews, an opinion with an explanation had a greater impact on guilt judgments than an opinion without explanation. ${ }^{100}$ If the testimony was research-based, then the presence or absence of an explanation had no impact. ${ }^{101}$ Results were similar for verdicts. ${ }^{102}$ Subjects who heard expert testimony deliberated longer than subjects who heard no expert testimony. ${ }^{103}$

An experiment by Katzev and Wishart ${ }^{104}$ concerned judicial commentary rather than expert psychological testimony. However, the content of the judge's commentary is quite similar to the content of the testimony provided by expert psychologists. In this experiment, subjects watched a forty-minute videotaped trial involving an eyewitnessed incident. There were three conditions of judicial commentary: a control condition in which the judge delivered standard instructions regarding issues of reasonable doubt; a condition in which the judge delivered standard instructions and a summary of the witnessing conditions (instruction + summary); and a condition in which the judge delivered standard instructions, the summary, and a comment on the psychological findings regarding eyewitness identification (instruction + summary + comment). Results indicated that the instruction + summary + commentary condition yielded significantly fewer predeliberation guilty verdicts and shorter deliberation times than did the control condition, with the instruction + summary condition falling in between with respect to both measures.

98. Maass, Brigham \& West, Testifying on Eyewitness Reliability: Expert Advice Is Not Always Persuasive, 15 J. Applied Soc. Psychology 207 (1985).

99. Id. at 213 .

100. Id. at 216.

101. Id.

102. Id. at 216,223 .

103. Id. at 219 .

104. Katzev \& Wishart, The Impact of Judicial Commentary Concerning Eyewitness Identifications on Jury Decision Making, $76 \mathrm{~J}$. Crim. L. \& Criminology 733 (1985). 
Fox and Walters ${ }^{105}$ exposed undergraduates to videotaped segments of eyewitness testimony and expert psychological testimony. The witness expressed either high or low confidence. Three conditions of expert testimony were crossed with the eyewitness conditions: no expert testimony, general expert testimony, and specific expert testimony. General expert testimony consisted of testimony similar to that used by Wells, Lindsay, and Tousignant, ${ }^{106}$ including identification accuracy rates obtained in previous experiments, general memory processes (acquisition, retention, and retrieval), and types of memory (sensory, short-term, and long-term). Specific testimony, on the other hand, did not address general memory processes. Instead, the expert psychologist discussed the effects of twelve specific factors known to influence eyewitness memory (for example, physical factors, exposure time, retention interval, stress, weapon focus, and the fairness of lineup procedures). In all expert testimony conditions, the expert psychologist discussed the weak relationship between confidence and accuracy. Results showed that jurors who heard expert testimony were significantly less likely to believe the witness than were jurors who did not hear expert testimony. A main effect was also found for witness confidence. There was no trend toward improved sensitivity to the weak confidenceaccuracy relationship associated with expert testimony. Specific testimony led to less belief in the eyewitness identification than did general testimony.

\section{E. Summary and Conclusions}

The research described above reveals several consistent findings about expert testimony. Most evident is the finding that reduced belief and fewer convictions are obtained if expert testimony is presented. ${ }^{107}$ However, it is not clear whether this reduced belief is due to skepticism (which it may appear to be on first examination) or to improved sensitivity to factors that might have impaired the witness' ability to make a correct identification. Fox and Walters; ${ }^{108}$ Hosch, Beck, and McIntyre; ${ }^{109}$ Maass, Brigham, and West; ${ }^{110}$ and Katzev and Wishart ${ }^{111}$ did not independently vary the presence of expert testimony and witnessing and identification factors that have important influences on eyewitness memory. Therefore, skepticism and sensitivity are perfectly confounded; and it is impossible to determine whether changes in conviction rates occur as a result of greater juror sensitivity or as a result of simple skepticism. Fox and Walters ${ }^{112}$ did vary the presence of expert

105. Fox \& Walters, The Impact of General Versus Specific Expert Testimony and Eyewitness Confidence Upon Mock Juror Judgment, 10 LAW \& HuM. BEHAV. 215 (1986).

106. Wells, Lindsay \& Tousignant, supra note 91 .

107. Fox \& Walters, supra note 105; Hosch, Beck \& McIntyre, supra note 97; Katzev \& Wishart, supra note 104; Loftus, supra note 93, at 13; Maass, Brigham \& West, supra note 98; Wells, Lindsay \& Tousignant, supra note 91 .

108. Fox \& Walters, supra note 105.

109. Hosch, Beck \& McIntyre, supra note 97

110. Maass, Brigham \& West, supra note 98.

111. Katzev \& Wishart, supra note 104.

112. Fox \& Walters, supra note 105. 
testimony and eyewitness confidence simultaneously, but there was no substantial improvement in juror sensitivity to the weak relationship between confidence and identification accuracy.

The only experiments that simultaneously and independently varied both witnessing factors that influence identification accuracy and the presence of expert testimony were those by Loftus ${ }^{113}$ and by Wells, Lindsay, and Tousignant. 14 Both show trends (albeit weak) toward improved sensitivity. Unfortunately, both studies are weak in realism and external validity.

Analyses of jury deliberations yield inconsistent effects. Hosch, Beck, and McIntyre; ${ }^{15}$ Loftus; ${ }^{116}$ and Maass, Brigham, and West ${ }^{117}$ all found that expert testimony increased the time that jurors spent deliberating about eyewitness evidence, while Katzev and Wishart ${ }^{118}$ found that less overall deliberation time was associated with expert testimony. But what can be made of deliberation time? Perhaps more time spent deliberating means that the jurors are attempting to reach an understanding of how a given factor might have influenced the witness' memory. If so, expert testimony, which presumably clarifies these issues, should lead to less deliberation time. On the other hand, perhaps extended deliberation time means that jurors are giving more thoughtful attention to the eyewitness evidence. Without more detailed content analyses, it is difficult to characterize the effect of expert testimony on jury deliberations.

One difficulty with this body of research is that the choice of dependent measures is not systematic. First, none of the experiments attempted to determine whether jurors remembered the eyewitness testimony and the expert testimony. Second, in experiments in which sensitivity and skepticism effects were not confounded, ${ }^{119}$ expert testimony had weak effects on juror sensitivity. Expert testimony may have improved juror knowledge about memory processes and the factors that influence memory, but the effect might have been attenuated due to poor integration skills. These experiments did not attempt to assess knowledge and integration separately.

In sum, the research supports Wells' conclusion: "At this point . . . we must acknowledge fully that there has not been a persuasive demonstration in the published literature that expert testimony on eyewitness matters improves the judgments of jurors."'120

\footnotetext{
113. Loftus, supra note 93.

114. Wells, Lindsay \& Tousignant, supra note 91.

115. See supra note 97.

116. See supra note 93 .

117. See supra note 98.

118. See supra note 104.

119. Fox \& Walters, supra note 105; Loftus, supra note 93; Wells, Lindsay \& Tousignant, supra note 91 .

120. Wells, supra note 15 , at 86 .
} 
VII

\section{Assessing the Effects of Expert Psychological Testimony}

In light of existing research, the concerns over the effects of expert testimony are valid but speculative. As experimental psychologists, we are able not only to offer expert testimony, but we are also in a position to evaluate empirically the influence of our expert testimony on juror decisionmaking. The next in our series of studies explores in detail the influence of expert testimony on the cognitive process of jurors.

\section{A. Overview}

The study by Cutler, Penrod, and Dexter ${ }^{121}$ improved on earlier experiments in a variety of ways. First, witnessing and identification conditions, witness confidence, and the presence of expert testimony were varied systematically, which allowed for tests of juror sensitivity and juror skepticism. Second, the study reflects Wells' recognition that it is important to examine the influence of expert testimony on variables in addition to the jury's final verdict: "There are other effects . . such as the effect of expert testimony on the process by which jurors reach a verdict ...."122 To determine the stage(s) at which expert testimony affects juror sensitivity, Cutler, Penrod, and Dexter explored juror memory, knowledge, inference, and decisionmaking.

This study used 538 undergraduate subjects who saw the same trial materials used in the earlier studies. However, expert psychological testimony was introduced as well. The expert testimony proceeded as follows. First, the witness' expertise was established, and the judge explained to the jury that the expert had been qualified at a previous hearing. Next, the expert described to the jury the case-relevant documents that he had studied before the trial. Finally, in full accord with Rule 702, the expert testified about the reconstructive nature of memory and the factors that affect memory at the perception, encoding, storage, and retrieval stages. In response to the defense attorney's questions, the expert discussed how the crime and the identification procedure might have influenced the witness' memory of the perpetrator. In all trials, the expert discussed the effects of stress and violence, the presence of a weapon, the passage of time, suggestive lineup procedures, and the relationship between confidence and identification accuracy. The expert discussed the effects of disguises only in trials in which the witness testified that the robber was disguised during the robbery.

Immediately following the defense's examination of the expert, the prosecution mounted a rigorous cross-examination and developed the following points:

(1) in all previous cases in which the expert testified, he testified solely for the defense;

121. Cutler, Penrod \& Dexter, The Eyewitness, the Expert Psychologist, and the Jury, supra note 59.

122. Wells, supra note 15 , at 89 . 
(2) the research about which the expert testified relied heavily on the use of college undergraduates as subjects and primarily used crime simulations rather than actual crimes;

(3) some psychologists express doubts about the reliability of the research findings and about the extent to which the research findings generalize to actual crime situations;

(4) stress and violence can sometimes improve memory;

(5) individuals can vary in their reactions to stress and violence;

(6) there is no way of knowing just how much stress a witness experienced at the time of a crime; there is no way of knowing how stress affected a given witness' memory;

(7) some studies show a direct relationship between eyewitness confidence and identification accuracy;

(8) even in studies in which a low correlation between confidence and accuracy is found, some witnesses make correct identifications and are highly confident;

(9) in simulated eyewitness experiments there are usually no actual consequences associated with false identifications or correct identifications; and

(10) the expert is being paid approximately sixty dollars per hour for his testimony.

\section{B. Design}

Four factors, each having two levels, were manipulated in the Cutler, Penrod, and Dexter experiment: witnessing and identification conditions, witness confidence, form of testimony, and whether or not the expert gave an opinion about the likelihood that the witness' identification was correct. Control groups, consisting of two levels of witnessing and identification conditions and two levels of witness confidence, added another four cells. In all, twenty separate videotaped trials were constructed.

1. Witnessing and Identification Conditions. In view of the established findings that jurors are insensitive to the factors that influence eyewitness identification accuracy, several factors were combined to form a powerful manipulation of witnessing and identification conditions ("WIC"). In the "poor WIC," the witness and police officer offered the testimony associated with the disguise, weapon present, fourteen-day retention interval, and suggestive lineup instructions. In the "good WIC," the witness and police offered testimony associated with the no-disguise, weapon hidden, two-day retention interval, and neutral lineup instruction conditions.

2. Witness Confidence. As in the earlier studies, the witness' confidence in the accuracy of her identification was varied. In half the trials, the witness testified that she was 80 percent confident, while in the other half she testified that she was 100 percent confident. 
3. Form of Testimony. In addition to testimony describing memory processes and factors that influence memory ("descriptive testimony"), in half the trials the expert discussed the findings of eyewitness experiments more quantitatively. In these trials, the expert described the effects of the relevant factors using verbal labels (that is, small, medium, or large) as well as percentages of correct and false identifications obtained in eyewitness identification experiments ("quantitative testimony"). Thus, jurors exposed to expert testimony either heard descriptive testimony or descriptive and quantitative testimony. The expert testimony experiment of Fox and Walters ${ }^{123}$ similarly varied whether the testimony was general or specific. Specific testimony was more effective than general testimony. Rather than examining whether quantitative testimony is more effective than descriptive testimony, the current experiment examines whether quantitative testimony improves upon descriptive testimony alone. The rationale for this variation is that the descriptive testimony would probably be given in most cases, while quantitative testimony would probably not be given unless it preceded the offer of more general testimony.

4. Expert Opinion. In half the trials, the defense attorney asked the expert for an opinion regarding the likelihood that the witness' identification of the defendant was correct. The expert gave the opinion on a scale ranging from 0 (least likely to be correct) to 25 (most likely to be correct). In the poor WIC trials the expert offered a rating of 7 ; in the good WIC trials the expert offered a rating of 20 . Witness confidence was not considered in the opinion because of its weak relationship with identification accuracy.

The manipulation of expert testimony, WIC, and witness confidence permitted separate tests of sensitization effects and skepticism effects. A skepticism effect would appear as a simple effect for expert testimony, such that jurors would be less likely to believe the identification if there is expert testimony than if there is not. A sensitization effect would emerge as a more complex interaction between WIC and expert testimony or between witness confidence and expert testimony. This interaction would show that witnessing and identification conditions have a stronger influence on jurors' judgments if there is expert testimony than if there is not. Witness confidence, on the other hand, would more strongly influence jurors' judgments if there is no expert testimony than if there is.

\section{Dependent Measures}

Memory for the witnessing conditions and for the expert testimony (for those who viewed expert testimony) was also assessed. Jurors were asked to recall the four stages of memory. In addition, knowledge about the effects of witnessing factors was assessed. For factors that were manipulated and held constant, jurors rated the extent to which the factor was likely to contribute to

123. Fox \& Walters, supra note 105 
a correct identification in both the specific and the general cases. To obtain measures of the jurors' inferences drawn from the eyewitness evidence, subjects rated the credibility of the eyewitness and the strength of both the prosecution's and the defense's cases. Decisions about verdict and probability ratings (the probability that the defendant was guilty, the probability that the witness correctly identified the robber, and the probability that under the circumstances the average person could make a correct identification) were also assessed.

Assessments of juror memory, knowledge, inference, and decisionmaking were designed to ascertain the point in the inferential chain where jurors go awry in evaluating eyewitness evidence. Is it that jurors do not remember the evidence, do not think the evidence is important, or fail to integrate the information effectively in their inferences or judgments? The answer to this question might vary as a function of the factors being examined. It is clear from the previous experiments that jurors, for the most part, recall the evidence and that the expert evidence does not influence their judgments. Jurors may believe that some factors are simply unimportant. They may view other factors as important, although without giving them sufficient weight to be reflected in the jurors' judgments.

\section{Results}

1. Juror Memory. Consistent with the earlier studies, jurors demonstrated superior memory for the evidence surrounding both the crime and the identification. This finding indicates that memory cannot be blamed for any lack of effects for WIC on jurors' judgments. In light of the high recall rates, it is also probably the case that expert testimony does little to improve memory. There is little room for improvement.

Overall memory for the expert testimony was also very good, although over half the subjects incorrectly reported that the expert discussed mugshot searches and the effects of the size of the lineup. This finding suggests an appreciable response bias toward reporting that the expert discussed a given factor, although accuracy rates were much higher for factors the expert actually discussed.

2. Analytic Strategy. WIC, witness confidence, and the various forms of expert testimony were examined for their influences on juror knowledge, inference, and decisions. One set of analyses explored how expert testimony influenced juror knowledge, inference, and decisionmaking, as compared to a control group. For this comparison, all expert conditions were combined. A second set of analyses explored the differential influences of form of expert testimony and expert opinion on juror knowledge, inference, and judgment. The descriptive testimony (with no expert opinion) was chosen as the condition against which all comparisons were made. One rationale for choosing the descriptive testimony condition is that it is the form most commonly employed in the courtroom. 
In discussing the results of this study we again make extensive use of $d$, the standardized measure of effect sizes. ${ }^{124}$ A $d$ of zero would indicate that two means are identical, while a $d$ of .3 (or -.3 ) would indicate a difference in means that, in the context of this study, is worthy of note.

3. Juror Knowledge. Juror knowledge refers to the juror's view of how an eyewitness factor influences identification accuracy. Consider, for instance, the ratings for the role of disguise. If jurors in the poor WIC (high disguise) rated the impact of disguise in the current case to be 5.0 on a 9 point scale (anchored at one end by "produces false identifications" and at the other end by "produces correct identifications"), and jurors in the good WIC (low disguise) also rated the impact of disguise to be 5.0 , this finding would indicate that jurors failed to recognize any influence of disguise on identification accuracy. Expert testimony would improve juror knowledge if the expert testimony either increases the influence of WIC on ratings of the effects of disguise, weapon visibility, retention interval, or lineup fairness, or attenuates the influence of witness confidence on confidence ratings.

WIC had a large effect on ratings of the role of disguise $(d=2.30$ ), indicating that jurors were well aware that disguises affect identification accuracy. It is therefore not surprising that expert testimony did not improve juror knowledge for the effects of disguise (that is, all interaction terms were statistically nonsignificant).

WIC had a trivial and nonsignificant effect on weapon visibility ratings $(d=$ .13 ), indicating that jurors were unaware of the effects of weapon focus on identification accuracy. WIC had a larger effect on weapon visibility ratings among jurors who heard expert testimony $(d=.41)$ than among jurors who heard no expert testimony $(d=-.03)$. This finding indicates that expert testimony improved juror knowledge about the effects of weapon focus. Descriptive testimony improved juror knowledge about the effects of weapon visibility on identification accuracy, but its sensitizing effect was attenuated by the addition of either quantitative testimony or an expert opinion.

WIC had a large effect on the knowledge ratings for retention interval ( $d=.78$ ), indicating that subjects were aware that recognition accuracy declines over time. No other effects were significant. WIC also produced a large effect on ratings of the importance of lineup instructions $(d=1.70)$, indicating that jurors considered lineup instructions to be important in assessing identification accuracy. Even though jurors were aware of the effects of lineup instructions, the addition of an expert opinion to descriptive testimony improved juror knowledge in comparison to the descriptive testimony alone ( $d=2.22$ and 1.39 , respectively).

Witness confidence had an appreciable effect on knowledge ratings for witness confidence ( $d=.72$ ), indicating that jurors believed that confidence is a good predictor of identification accuracy. Confidence was viewed as less

124. For a discussion of $d$, see supra Part III.B. 
relevant among jurors who heard expert testimony $(d=.52)$ than among jurors who heard no expert testimony $(d=.84)$. Descriptive testimony sensitized jurors to the weak confidence-accuracy relation in comparison to those who heard no expert testimony $(d=.17$ and .84 , respectively).

These analyses show that jurors believed that disguise, retention interval, and lineup instructions all have appreciable effects on identification accuracy, but jurors were unaware of the effects associated with weapon visibility. As in previous experiments, jurors felt that witness confidence was an important determinant of identification accuracy. The presence of expert testimony in any form improved juror knowledge of the effects of weapon visibility, lineup fairness, and witness confidence. The addition of an expert opinion to descriptive testimony, in comparison to descriptive testimony alone, improved juror knowledge for lineup fairness but had a negative impact on juror knowledge for the weapon focus effect. The descriptive testimony appeared to be superior to the descriptive-plus-quantitative testimony in improving juror knowledge of the weapon focus effect and the weak predictive validity of witness confidence. Of course, knowledge of these factors is no guarantee that the knowledge will be successfully employed when making inferences and judgments.

4. Juror Inferences. Inferences refer to the jurors' perceptions of the credibility of the eyewitness and the strengths of the prosecution's and defense's cases. Ratings of credibility varied directly with the witness' confidence level $(d=.37)$, but confidence was given less weight in determining witness credibility if the expert testified $(d=.11)$ than if no expert testified $(d=.52)$. WIC also affected eyewitness credibility ratings to a greater extent if an expert testified $(d=.34)$ than if no expert testified $(d=-.01)$, indicating that expert testimony improved juror sensitivity to WIC effects. In fact, the descriptive testimony led to a slight reversal effect for witness confidence.

The jury perceived the prosecution's case as stronger in the good WIC $(d=.30)$, but WIC had more of an effect on the perceived strength of the prosecution's case if an expert testified $(d=.54)$ than if no expert testified $(d=.15)$. The prosecution's case was perceived as stronger if the witness was 100 percent confident $(d=.20)$. The confidence of the witness was a more powerful determinant of the strength of the prosecution's case if the expert gave descriptive-plus-quantitative-plus-opinion testimony $(d=.64)$ than if the expert gave only descriptive testimony $(d=-.16)$.

The defense's case was perceived as stronger in the poor WIC $(d=-.30)$. WIC had a stronger influence on defense case strength ratings if the expert testified $(d=-.53)$ than if no expert testified $(d=-.13)$.

In sum, although jurors indicated that they believed that several of the factors included in the WIC manipulation would influence eyewitness performance, WIC had negligible effects on juror inferences without expert testimony. When the expert testified, however, jurors demonstrated 
significant sensitivity to WIC when drawing inferences about the credibility of the eyewitness and when determining the strength of the prosecution's and defense's cases. The form of expert testimony and the offering of an expert opinion did not consistently influence juror sensitivity to WIC. The presence of expert testimony in some form also reduced jurors' heavy reliance on witness confidence when drawing inferences about the credibility of the eyewitness and the strength of the prosecution's case. The presence of expert testimony in some form also increased the apparent strength of the defense's case, but did not increase juror skepticism about the eyewitness' credibility.

5. Juror Decisionmaking. WIC had an appreciable effect on jurors' judgments about the accuracy of the identification $(d=.30)$. Jurors were more likely to judge the identification as accurate in the good WIC than in the poor WIC. However, WIC had a large influence on jurors' judgments if the expert testified $(d=.53)$, but a negligible effect if no expert testified $(d=.12)$. Jurors were also more likely to judge the identification as accurate if the witness was 100 percent confident than if the witness was 80 percent confident $(d=.25)$. When jurors heard descriptive testimony, probability ratings varied inversely with the confidence of the witness $(d=-.45)$. This was not true with the other forms of testimony. The descriptive testimony also improved juror sensitivity to WIC to a greater extent $(d=.94)$ than did the descriptiveplus-quantitative testimony, which showed a small sensitization effect $(d=.08)$. Expert testimony and form of expert testimony produced trivial main effects on probability ratings. Thus, there was no evidence of a skepticism effect.

WIC had a main effect on verdict such that more convictions were obtained with good WIC $(d=.29)$. The descriptive testimony led to an inverse relation between witness confidence and proportion of guilty verdicts $(d=-.29)$, though other forms of testimony did not. Once again, WIC had a stronger influence on verdicts if the expert gave descriptive testimony $(d=.94)$ than if no expert testified $(d=.20)$. This finding indicates that descriptive expert testimony sensitized jurors to the influence of WIC on identification accuracy. The descriptive testimony had a greater sensitization effect $(d=.94)$ than did the descriptive-plus-quantitative testimony $(d=.08)$ and the descriptive-plusquantitative-plus-opinion testimony $(d=.24)$. Expert testimony and form of expert testimony produced trivial main effects on verdicts, again indicating no skepticism effect.

6. Summary of Results. Expert testimony clearly improved juror sensitivity to WIC in comparison to the control condition, and descriptive testimony was the most effective form of testimony in this respect. The effects of expert testimony on the relation between witness confidence and jurors' decisions, however, are less clear-cut. If no expert testimony was given, witness confidence produced an appreciable effect on jurors' judgments. And although descriptive testimony improved juror sensitivity to WIC, it produced an inverse relation between witness confidence and probability ratings and 
between witness confidence and verdict. In contrast, the descriptive-plusopinion and descriptive-plus-quantitative-plus-opinion conditions produced positive relationships. It is noteworthy that there were essentially no skepticism effects: Neither the presence of expert testimony nor the type of expert testimony had any appreciable effect on credibility ratings for the eyewitness, probability ratings, or verdict.

\section{E. The Problem of Knowledge Versus Integration}

It is clear from the above analyses that jurors do indeed possess some knowledge of the effects of disguise, retention interval, and suggestive lineup instructions. However, jurors are unaware of the influence of weapon visibility and are unaware that confidence is a weak predictor of identification accuracy. Thus, poor knowledge is partly responsible for the lack of juror sensitivity. Evidence that jurors lack integration skills emerges from the findings that the influence of WIC and confidence diminish between the knowledge and inference stages. If jurors were able to integrate the evidence appropriately, then the effect-sizes for WIC and witness confidence in the noexpert conditions would remain relatively constant in magnitude across juror knowledge, inference, and judgment items. The clear attenuation of effectsizes from the knowledge to the inference stages, for both WIC and witness confidence, indicate difficulties in integrating evidence. Moreover, WIC, without expert testimony, had a trivial influence on inferences and decisions (all $d$ 's were no greater than .20). Thus, both lack of appropriate knowledge and poor integration skills jointly contribute to produce poor juror sensitivity to eyewitness evidence.

This experiment indicates that expert testimony improved juror knowledge. Expert testimony increased the juror's reliance on witnessing and identification conditions when drawing inferences about the credibility of the eyewitness and the strength of the prosecution's and defense's cases, and decreased juror reliance on witness confidence when drawing inferences about the credibility of the eyewitness and the strength of the prosecution's case. At the decisionmaking stage, expert testimony facilitated greater reliance on witnessing and identification conditions in determining the probability that the identification was correct and in shaping the verdict. There was no evidence to suggest that expert testimony promotes skepticism toward the eyewitness' credibility, the accuracy of the identification, or the defendant's culpability (all $d$ 's were less than .10).

There were few consistent effects of various types of expert testimony on juror knowledge. On balance, the descriptive testimony looked most effective. All expert testimony conditions were equally effective at sensitizing witnesses to the effects of witnessing and identification conditions at the inference stage. At the decisionmaking stage, the descriptive and the descriptive-plus-opinion conditions were most consistent in sensitizing jurors to the effects of witnessing and identification conditions. 


\section{F. Conclusions and Implications}

This study provides considerable evidence bearing on the controversies surrounding expert psychological testimony. Scholars have debated whether psychological knowledge about factors that influence memory is within the ken of the jury. The research described here indicates that jurors have some but not all of the necessary knowledge. A more deeply rooted problem, however, is that because of difficulties associated with integrating evidence, even knowledge within the ken of the jury is not reflected in the jurors' judgments.

Do the effects of expert testimony on jurors' judgments confirm the expectations of psychologists and legal scholars? Does expert testimony produce confusion, sensitivity, or skepticism? There was some evidence of juror confusion-the inexplicable reversal effects produced at the decisionmaking stage. Perhaps the most compelling evidence against juror confusion is the striking impact of expert testimony. There were only two dependent measures (of ten) on which expert testimony had no effectsknowledge for disguise and retention interval effects. These results are understandable given that jurors had pre-existing knowledge of these effects. The memory tests revealed that jurors recalled virtually all of the relevant evidence and the expert testimony, but our memory test for expert testimony might not have been sufficiently sensitive to detect juror confusion.

With respect to sensitization and skepticism, there was considerable evidence for the former and no evidence for the latter. Scholars view improved sensitization as a desirable consequence of expert testimony. ${ }^{125}$ While the desirability of a skepticism effect remains in debate, the results of this study suggest that it should not be a matter of concern. With respect to previous research that has confounded the sensitization and skepticism effects, ${ }^{126}$ the current results suggest that effects were due to sensitization.

While the results of this experiment indicate that expert testimony can have salutary effects, several important empirical questions remain open. One critical issue involves cases in which both prosecution and defense hire experts. The prosecution expert could, for example, stress the limitations of the research and the difficulties with generalizing from the restricted samples and experimental situations characteristic of eyewitness studies. If expert testimony on eyewitness identification were admitted regularly, would the court become a forum for a battle among experts, as McCloskey and Egeth suggest? ${ }^{127}$ Furthermore, in a battle of the experts, will the jury discount one expert's testimony on the basis of an opposing expert's testimony? Will the jury be confused by the contradictory testimony of the experts?

The influence of expert testimony on the jury deliberation process should be examined as well. Maass, Brigham, and West treated pre- versus post-

125. Wells, supra note 51.

126. See supra text accompanying notes 107-11

127. McCloskey \& Egeth, supra note 13, at 559 
deliberation judgments as an independent variable and found that effects for expert testimony were exaggerated following deliberation. ${ }^{128}$ This finding implies that the sensitization effects observed here might underestimate the effect that would emerge after deliberation. Further research is also needed to explore the effectiveness of other forms of expert testimony as well as other safeguards, such as carefully constructed judicial instructions, for protecting against false convictions based on mistaken identifications.

\section{VIII}

\section{Alternative Forms of Expert Advice for Juries}

Additional studies by Cutler, Dexter, and Penrod ${ }^{129}$ sought to address some of the questions outlined above. The studies examine the influence of a court-appointed expert and opposing experts and of judical instructions concerning eyewitness memory. The Telfaire instruction is a commonly used instruction for directing the jury's attention toward presumably relevant eyewitness factors. ${ }^{130}$ The only previous test of the Telfaire instruction found that it had minimal effects on the decisions of jurors. ${ }^{131}$

\section{A. Research Design}

These studies used two levels of WIC, good versus poor, which were crossed with two levels of witness confidence, 80 percent versus 100 percent confidence that the identification was correct. The trial was the same one used in the preceding research, and the WIC and witness confidence manipulations were essentially the same. Two hundred ninety undergraduates served as subjects in the study. The WIC and confidence factors were crossed with six forms of expert advice:

The no expert advice condition served as a control against which the effects of other forms of expert advice could be compared.

The defense-hired expert condition was identical to that used in the previous study and included the same rigorous cross-examination.

The testimony of the court-appointed expert was identical to that of the defense-hired expert; however, the court-appointed expert was introduced and questioned by the judge. The court-appointed expert condition was created by replacing the defense and prosecuting attorneys' questions with the judge's examination and crossexamination questions; thus, the expert's testimony was identical across expert testimony conditions.

Telfaire instructions focused the jury's attention on thirteen witnessing and identification factors, including the witness's confidence, the circumstances under

128. Maass, Brigham \& West, supra note 98 , at 215.

129. Cutler, Dexter \& Penrod, Expert Testimony and Jury Decisionmaking: An Empirical Analysis, 7 Behav. Sci. \& Law 215 (1989); Cutler, Penrod \& Dexter, Expert Testimony on Eyewitness Identification: The Hired Gun, the Friend of the Court, the Battling Experts, and the Judge, supra note 59 .

130. See, e.g., Moore v. Tate, 882 F.2d 1107 (6th Cir. 1989); U.S. v. Bear, 883 F.2d 1382 (8th Cir. 1989); U.S. v. MCNeal. 865 F.2d 1167 (10th Cir. 1989).

131. Greene, Eyeuitness Testimony and the Lise of Cautionary Instructions, 8 U. Bridgeport L. Rev. 15 (1987) (Symposium on Eyewitness Identification Testimony). 
which the identification was made, and the length of time between the crime and the identification. ${ }^{132}$

The prosecution-hired opposing expert established his credentials (which were comparable to the defense-hired expert's) and testified to the following points: (1) eyewitness research techniques are not always reliable; (2) many psychologists believe that, because of limitations in research methods, the results of many eyewitness studies do not generalize to actual crime settings; (3) studies of violence, weapon focus, and witness confidence produce mixed results; (4) there is no way to know how much stress was experienced by a witness; (5) there is no way to assess the fairness of an actual lineup; and (6) there is no way to know whether a specific witness is accurate or inaccurate. During cross-examination, the opposing expert admitted that: (1) criticisms of the eyewitness studies are directed toward the applicability of the research to criminal settings and not toward the quality of the research; (2) the quality of eyewitness research meets scientific standards; and (3) his views represent a minority of experimental psychologists, while the defense-hired expert's views represent the majority.

Defense-hired expert plus judge's instructions. The defense-hired expert testified and the Telfaire instructions were given.

\section{B. Results}

1. Evidence and Confidence Effects. WIC had no significant effects on verdicts or on evaluations of eyewitness credibility or of the accuracy of the eyewitness identification. In contrast, witness confidence had a significant effect on all of these judgments (for example, 39 percent of jurors convicted in the 80 percent confidence condition versus a 49 percent conviction rate in the 100 percent confidence condition).

2. Skepticism Effects. In comparison to the no advice control group, significant and consistent skepticism effects were obtained for the opposing experts and court-appointed expert conditions. The witness credibility rating in the no expert condition was 6.2 versus 5.6 in the court-appointed condition and 5.2 in the opposing experts condition. Comparing verdicts, 42 percent convicted in the opposing experts condition, 30 percent in the courtappointed expert condition, and 57 percent in the no expert condition. Skepticism effects for the remaining conditions were small, inconsistent, and statistically nonsignificant.

3. Sensitization. The opposing experts condition produced the strongest and only statistically significant sensitization effect. Subjects in the opposing experts condition relied most on witnessing and identification conditions and least on witness confidence when evaluating witness credibility and rendering verdicts. The remaining expert advice conditions also reduced juror reliance on witness confidence when compared with the no advice condition, but these differences were not statistically significant.

4. Replications. The effects of the defense-hired expert in the current study were comparable to those of the preceding study. In both instances the defense-hired expert produced trivial and nonsignificant skepticism effects.

132. Cutler, Penrod \& Dexter, The Eyewitness, the Expert Psychologist, and the Jury, supra note 59. 
Although in the current study the defense-hired expert produced nonsignificant sensitization effects, in three of the four sensitization tests (sensitization to witness confidence and to WIC with each of two dependent measures), the sensitization effects were actually larger in the current experiment than in the preceding experiment. The earlier study included data from 538 subjects while the current study had a more modest sample size of 290 , and thus the statistical tests were less sensitive in the latter. We conclude that the results of the earlier study are replicated.

\section{Discussion}

In summary, the defense-hired expert produced no skepticism, and, as in Cutler, Penrod, and Dexter, ${ }^{133}$ produced some sensitization to WIC and witness confidence. In contrast, the court-appointed expert failed to sensitize jurors to relevant witnessing and identification conditions, and promoted substantial skepticism about the accuracy of the identification. The opposing experts produced both skepticism about the identification and sensitization to WIC. Ironically, the sensitization effects produced by the opposing experts were stronger in magnitude than the sensitization effects produced by the defense-hired expert alone.

Because the content of the defense-hired and court-appointed expert testimony was identical (it was the same videotaped footage), the differences in skepticism and sensitization must be attributable to some aspect of the defense-hired expert's adversarial status. Perhaps because the defense-hired expert was treated like any other defense witness (that is, the expert was examined by the defense attorney and cross-examined by the prosecuting attorney), subjects evaluated his testimony together with the testimony of other witnesses. This hypothesis might account for the interaction effects between expert testimony, witnessing and identification conditions, and witness confidence (that is, sensitization effects) observed in the Cutler, Penrod, and Dexter study and in the current experiment. In contrast, perhaps because the court-appointed expert was treated differently from other witnesses, having been questioned only by the judge, subjects considered his testimony independent of the other witness' testimony.

The stronger skepticism and sensitization effect for the opposing experts in comparison to the defense-hired expert is counterintuitive. The prosecution-hired expert made an admirable attempt to discredit the defensehired expert's testimony, but this attempt substantially backfired. Perhaps subjects reasoned that the eyewitness evidence must really be important if both sides had exerted the effort to hire expert psychologists, and this reasoning led jurors to scrutinize more carefully the eyewitness evidence and the expert testimony.

The set of Telfaire instruction findings raises significant doubts about its efficacy. First, the Telfaire instructions produced no skepticism or sensitization 
effects, either alone or in combination with defense-hired expert testimony. Indeed, there was a consistent trend toward reduced sensitization to witnessing and identification conditions associated with the Telfaire conditions. The fact that the Telfaire instructions, alone and in combination with expert testimony, reduced subjects' reliance on witness confidence should be considered in light of the instruction's content, which encourages subjects to rely more heavily on witness confidence. These null effects are noteworthy given that the Telfaire instruction is commonly used in eyewitness cases. Thus, we conclude, as does Greene, ${ }^{134}$ that the Telfaire instructions ineffectively protect the defendant against mistaken conviction. Greene's revised instruction appears to be more effective and indeed deserves further investigation.

The findings have some additional implications concerning the strategies of both defense and prosecuting attorneys. The defense attorney can, in some circumstances, harm the case by hiring an expert to testify about eyewitness identification. As demonstrated above, presentation of expert testimony together with good witnessing and identification conditions can lead to an increased likelihood of conviction. The defense-hired expert is apparently successful at reducing the likelihood of conviction if the witnessing and identification conditions appear likely to facilitate a false identification or if the witness is highly confident. From the prosecution's standpoint, hiring an expert to oppose the defense-hired expert, as demonstrated in the current experiment, can be detrimental to the state's case. On the other hand, a prosecution expert who testifies about the strengths of an eyewitness identification may well increase conviction rates. To date, there has been no empirical test of whether a prosecution-hired expert can be effective for the state's case. More research is needed to identify the circumstances that moderate the effectiveness of the defense- and prosecution-hired experts in cases involving eyewitness identification and in cases involving other forms of expert testimony.

\section{IX}

\section{Conclusion}

In cases where the reliability of an eyewitness identification is in question, expert psychologists are being called with increasing regularity to educate jurors about memory processes and factors that can influence eyewitness identification accuracy. There is considerable debate within both the legal and psychological communities about the admission of such testimony. Proponents and opponents of expert testimony disagree over (1) whether there is an adequate scientific foundation for the presentation of such testimony, (2) whether the evidence provided by the expert is beyond the ken of the jury, and (3) whether expert testimony is likely to improve jury

134. Greene, supra note 131 
decisionmaking. We have reported a series of studies designed to examine these three issues empirically.

The first study was a quantitative "meta-analysis" of a large body of experiments conducted by researchers interested in facial recognition performance. This study indicated that factors investigated by researchers have substantial and reliable effects on eyewitness performance and that experimental laboratory findings do not differ significantly from findings produced in field settings.

In a second set of studies, mock jurors were shown realistic videotaped criminal trials in which the primary evidence was the identification of the defendant by an eyewitness. The evidence surrounding the crime (for example, the disguise of the perpetrator and the extent to which the witness was threatened) and the identification procedures (for example, the time delay between the crime and the identification, as well as the procedures used to construct and conduct the lineup parade) were manipulated through the testimony of the eyewitness and the police officer in charge of the investigation. These studies examined the extent to which juror decisions were influenced by the variations in the crime and the identification. The studies indicate that jurors were not influenced by the factors that normally influence identification accuracy-with the exception that judgments were influenced by the confidence of the eyewitness. Unfortunately, a number of studies indicate that witness confidence is only weakly related to the accuracy of the identifications.

In the third set of studies, the videotaped trials included expert psychological testimony. In the first study of this set, expert testimony improved the sensitivity of jurors to eyewitness evidence. If expert testimony was presented, jurors took the witnessing and identification factors into consideration to a greater extent, and the confidence of the witness to a lesser extent, than if no expert testimony was presented. The study also showed that expert psychological testimony did not increase juror skepticism about eyewitness evidence. The second experiment examined the influence of different forms of expert testimony and judicial instructions on jurors' judgments. A defense-hired expert produced some sensitization toward witnessing and identification conditions but no skepticism toward the accuracy of the identification. A court-appointed expert produced only skepticism. Opposing experts (defense- and prosecution-hired) produced the largest effects on both sensitization and skepticism, while judicial instructions designed to aid the jury in evaluating eyewitness evidence had no beneficial effect on jury decisionmaking.

Overall, these studies indicate that expert psychological testimony can improve jury decisionmaking by assisting jurors in the task of appropriately evaluating eyewitness evidence, and that the improvements in juror sensitivity can be secured without increasing juror skepticism. 
